\title{
An Extensive Invasive Intracranial Human Glioblastoma Xenograft Model
}

\section{Role of High Level Matrix Metalloproteinase 9}

\author{
Yunge Zhao, ${ }^{*}$ Aizhen Xiao, ${ }^{*}$ Charles G. diPierro, ${ }^{\dagger}$ \\ Joan E. Carpenter, ${ }^{*}$ Rana Abdel-Fattah, ${ }^{*}$ \\ Gerard T. Redpath, ${ }^{*}$ Maria-Beatriz S. Lopes, ${ }^{*}$ \\ and Isa M. Hussaini* \\ From the Departments of Pathology, and Molecular Physiology \\ and Biological Physics, ${ }^{\dagger}$ University of Virginia, Charlottesville, \\ Virginia
}

The lack of an intracranial human glioma model that recapitulates the extensive invasive and hypervascular features of glioblastoma (GBM) is a major hurdle for testing novel therapeutic approaches against GBM and studying the mechanism of GBM invasive growth. We characterized a high matrix metalloproteinase-9 (MMP-9) expressing U1242 MG intracranial xenograft mouse model that exhibited extensive individual cells and cell clusters in a perivascular and subpial cellular infiltrative pattern, geographic necrosis and infiltrating tumor-induced vascular proliferation closely resembling the human GBM phenotype. MMP-9 silencing cells with short hairpin RNA dramatically blocked the cellular infiltrative pattern, hypervascularity, and cell proliferation in vivo, and decreased cell invasion, colony formation, and cell motility in vitro, indicating that a high level of MMP-9 plays an essential role in extensive infiltration and hypervascularity in the xenograft model. Moreover, epidermal growth factor (EGF) failed to stimulate MMP-9 expression, cell invasion, and colony formation in MMP-9-silenced clones. An EGF receptor (EGFR) kinase inhibitor, a RasN17 dominant-negative construct, MEK and PI3K inhibitors significantly blocked EGF/EGFR-stimulated MMP-9, cell invasion, and colony formation in U1242 MG cells, suggesting that MMP-9 is involved in EGFR/ Ras/MEK and PI3K/AKT signaling pathway-mediated cell invasion and anchorage-independent growth in U1242 MG cells. Our data indicate that the U1242 MG xenograft model is valuable for studying GBM extensive invasion and angiogenesis as well as testing anti-invasive and anti-angiogenic therapeutic ap- proaches. (Am J Pathol 2010, 176:3032-3049; DOI: 10.2353/ajpath.2010.090571)

Glioblastoma (GBM) is the most aggressive glioma and is associated with extensive invasion into surrounding brain tissue. The highly invasive nature of GBMs precludes total surgical resection and contributes to the recurrence of GBM. Effective treatments depend on experimental models that closely resemble human GBM characteristics for testing new therapy and providing an accurate understanding of the molecular basis of widespread glioma invasion. Unfortunately, mechanistic investigations into GBM invasion and drug development have been hampered by a paucity of representative experimental models that recapitulate the invasive GBM tumor growth.

A number of animal models have been developed by intracranial implantation of human GBM cell lines in rodents to test novel therapeutic agents targeting different features of human GBM, ie, angiogenesis and invasion, ${ }^{1-5}$ and to study the mechanisms of tumor invasiveness. ${ }^{6,7}$ Human U251 and U87 GBM xenograft animal models are the most common GBM animal models and have been widely used to test therapeutic approaches to human GBM cells in vivo ${ }^{8-10}$ since they recapitulate some features of the human GBM, ie, tumor formation, necrosis, or angiogenesis. Moreover, the U87 model has also been applied and proved useful when assessing GBM angiogenesis and anti-angiogenic therapeutic approaches. ${ }^{11-13}$ In addition, the rat C6 glioma cell animal model shows diffuse brain invasion. ${ }^{14,15}$ However, tumor inva-

Supported by the Farrow Fellowship and the University of Virginia Cancer Center Support grant, P30 CA44570 (to Y.G.Z.) and National Institutes of Health grants NS35122 and CA90851 (to I.M.H.).

Accepted for publication February 24, 2010.

Supplemental material for this article can be found on http://ajp. amjpathol.org.

Address reprint requests to Yunge Zhao, M.D., Ph.D., Department of Pathology, University of Virginia, Charlottesville, VA, 22908, E-mail: yz5u@virginia. edu. 
sion in these models is not as extensive as in spontaneous GBM in humans, although peritumoral infiltration of the brain parenchyma ${ }^{16}$ and individual cells infiltration ${ }^{14,15}$ were detected around the tumor. In addition, no any individual GBM model assembles extensive infiltration, necrosis, and vascular proliferation.

These nonextensive infiltrative GBM models have made it difficult to predict the outcome of novel therapies. Even though novel therapies have been proven successful to reduce the tumor mass in these GBM models, they may fail to inhibit the tumor invasion when they are translated to human patients. There is therefore a compelling need for more accurate and reproducible intracranial tumor models, which should recapitulate key features of the human GBM, especially extensive invasive nature of these tumors.

Tumor invasiveness involves proteolytic degradation of the extracellular matrix (ECM) as well as depends on the adhesion, mobility, proliferation, apoptosis, and senescence of tumor cells. Increased protease expression has been correlated with the invasive properties of invading cells. ${ }^{17-20}$ The two classes of proteases involved in GBM tumor invasion are matrix metalloproteinases (MMPs) and serine proteases. Increased expression/activity of MMP-9 has been found in anaplastic astrocytomas and $\mathrm{GBM}^{19,21,22}$ and correlated with the highly malignant progression of human gliomas in vivo. ${ }^{19}$ The activity level of MMP-9 is increased during the growth of glial tumors in nude mice following intracerebral injection of glioblastoma cells. ${ }^{23}$ Even though in vitro and in vivo experimental models demonstrated that inhibiting MMP-9 function significantly decreased SNB19 glioma cell invasion in vitro and tumor formation in the xenograft model, ${ }^{24}$ the SNB19 glioma cells-formed tumors displayed well-circumscribed tumor mass without extensive infiltration. Therefore, the mechanism underlying the association of MMP-9 expression and extensive invasion of GBM remains to be elucidated.

Epidermal growth factor receptor (EGFR) activation increases MMP-9 expression and activity in other cancer cell types through the JAK3/ERK pathway and PI3K pathway, ${ }^{25-27}$ and epidermal growth factor (EGF) is expressed in normal brain, benign, and malignant glia tumors. ${ }^{28}$ EGFR overexpression/amplification occurs in $40 \%$ to $60 \%$ of all primary GBMs and has been associated with poor prognosis. ${ }^{29-32}$ Both short interfering (si)RNA-targeted EGFR and transfection of EGFR cDNA antisense in the human malignant glioma cell line TJ905 decreased expression and enzymatic activities of MMP-9, as well as cell invasion. ${ }^{33}$ However, the role of EGF-stimulated MMP-9 and the signal pathway in GBM cell invasion have not been reported.

In this study, we characterized an extensive infiltrative human glioma xenograft mouse model. High levels of MMP-9 contributed to single, clustered, perivascular, and subpial cellular infiltration as well as infiltrating tumorinduced vascular proliferation. Our U1242 MG xenograft model would be a useful experimental and preclinical model for studying the mechanisms underlying the extensive invasion of GBM and testing novel therapeutic agents. Finally, MMP-9 was essential for the EGFR/Ras/
MEK and PI3K/AKT-dependent increase in invasion and colony formation of U1242 MG cells.

\section{Materials and Methods}

\section{Antibodies and Reagents}

Rabbit anti-human MMP-9 and MMP-2 antibodies, EGFR antibody, and mouse anti-human phospho-Akt (Ser473) antibody were purchased from Cell Signaling Technology (Beverly, MA). Goat anti-PECAM-1 antibody for immunohistochemistry was purchased from Santa Cruz Biotechnology Inc. (Santa Cruz, CA). Mouse anti-human tubulin antibody, lentiviral short hairpin (sh)RNA MMP-9- constructs, type IV collagen, and EGF were obtained from Sigma Chemical (St. Louis MO). MEK inhibitor (UO 126), EGFR kinase inhibitor AG1478, PI3K inhibitor LY 294002, MMP broad spectrum inhibitor GM6001, MMP-9 functionblocking antibody (clone 6-6B), and pro-MMP-9 enzyme are products of Calbiochem (San Diego, CA). A PCR kit was obtained from Invitrogen Corp. (Carlsbad, CA). The mouse anti-human Ki-67 antibody was from Dako (Carpinteria, CA), and the mouse anti-human vimentin antibody was from Biogenex Laboratory Inc (San Ramon, CA).

\section{Cell Culture}

Normal human astrocytes (NHA) were obtained from Clonetic and grown in Clonetics EBM (Endothelial Cell Basal Media, No.CC-2131) supplement with hydrocortisone (1 $\mu \mathrm{g} / \mathrm{ml})$, hEGF (20 ng/ml), insulin $(25 \mu \mathrm{g} / \mathrm{ml})$, progesterone (25 $\mathrm{ng} / \mathrm{ml})$, transferrin $(50 \mu \mathrm{g} / \mathrm{ml})$, and $5 \%$ fetal bovine serum. U1242 MG, which was originally established from a highly malignant human glioma, ${ }^{34}$ was obtained from Dr. A.J. Yates (Ohio State University), U251 MG from Dr. D.D. Bigner (Duke University), U87 MG from ATCC, and primary GBM tumor cells (\#8HGBM) from Mayo Clinic (Rochester, MN). U1242 MG cells have p53 mutation (mu-p53) but wild-type PTEN (wt-PTEN). The U87 MG cells have a mutant PTEN (mu-PTEN), but wild-type p53 (wt-p53) and U251 MG cells have both mu-p53 and mu-PTEN. ${ }^{35}$ U87 MG, U251 MG, U1242 MG, and HGBM\#8 cells were grown in $\alpha$-Minimum Essential Medium media (Invitrogen) supplemented with 10\% fetal bovine serum, 100 units $/ \mathrm{ml}$ penicillin, and $100 \mu \mathrm{g} / \mathrm{ml}$ streptomycin penicillin/streptomycin in a humidified incubator containing $5 \% \mathrm{CO}_{2}$ at $37^{\circ} \mathrm{C}$.

\section{Reverse Transcription-PCR}

RNA was extracted from the cells, nonneoplastic temporal lobes (TLs) and GBM patient specimens by Trizol according to manufacturer protocols (Invitrogen). The reverse transcriptase (RT)-PCR was performed as previously described. ${ }^{35,36}$ The MMP-9 forward primer was 5'-ACCCAATCTCACCGACAG-3' and the reverse primer was $5^{\prime}$-CAAAGGCGTCGTCAATCA-3'; the $\beta$-actin forward primer was 5'-CACCATGGATGATGATATCG-3' and the reverse primer was 5'-TGGATAGCAACGTA- 
CATGG-3'; and the EGFR forward primer was 5'-AAACTGCTGGGTGCGGAAGA-3' and the reverse primer was 5' - CGTGGAGGGGCTGCTGAAGA-3'.

\section{Real-Time Quantitative PCR}

Real-time quantitative (RQ)-PCR was performed using TaqMan probe-based chemistry (Applied Biosystems) according to our previous report. ${ }^{35}$ The MMP-9 primers and probe were designed against GenBank-published sequences in association with Primer Express (Applied Biosystems). The MMP-9 mRNA was normalized to histidine-containing phosphocarrier protein-response regulator/ $\beta$-actin/Hypoxanthine-guanine phosphoribosyltransferase.

\section{Western Blotting}

The conditioned media were collected from the cultured cells to determine the level of secreted MMP-9 and MMP-2. The cultured cells or TLs or GBM patient specimens were lysed according to our previous report. ${ }^{37}$ Equal amounts of total protein $(30 \mu \mathrm{g})$ were loaded and rabbit anti-human MMP-2 and -9 antibodies and rabbit anti-human EGFR antibody were used. The mouse antihuman $\alpha$-tubulin antibody was also used as loading control.

For phosphorylation studies, the incubation was terminated by the addition of ice-cold PBS containing 0.2 $\mathrm{mmol} / \mathrm{L}$ sodium orthovanadate to the culture. PBS was then aspirated, and cells were solublized with $1 \%$ Triton $\mathrm{X}-100$ and $0.2 \%$ Nonidet P-40 in the presence of 2 $\mathrm{mmol} / \mathrm{L}$ EDTA, $100 \mu \mathrm{mol} / \mathrm{L}$ phenylmethylsulfonyl fluoride, $5 \mu \mathrm{g} / \mathrm{ml}$ leupeptin, $1 \mu \mathrm{g} / \mathrm{ml}$ aprotinin, $50 \mathrm{mmol} / \mathrm{L}$ sodium fluoride, $5 \mathrm{mg} / \mathrm{ml}$ dithiothreitol, and $0.2 \mathrm{mmol} / \mathrm{L}$ sodium orthovanadate. The $1 \%$ Triton X-100 extract was electrophoresed, and immunoblotted with anti-phospho-Akt (Ser473) antibody.

\section{Gelatin Zymography}

Total proteins were extracted from cells, TLs, and GBM patient specimens according to our previous report. ${ }^{22}$ The conditioned serum-free media from cell culture or from the upper chamber of invasion insert were collected and equal amounts of proteins $(30 \mu \mathrm{g})$ were loaded in each lane for MMP-2 and -9 gelatinolytic activity detection using gelatin zymography as described previously. ${ }^{36}$

\section{Immunohistochemical and Immunocytochemical Staining}

Immunohistochemistry and immunocytochemistry were performed as previously reported. ${ }^{38}$ Briefly, for immunocytochemistry, cells were fixed in 50\% methanol/50\% acetone for 15 minutes and permeated with $1 \%$ Triton X-100 in Tris-buffered saline for 15 minutes. For immunohistochemistry, $5-\mu \mathrm{m}$ sections of formalin-fixed paraffinembedded (FFPE) tissues were dewaxed with xylene and rehydrated in $100 \%$ and $95 \%$ ethanol. Antigen unmasking was performed by boiling slides in $10 \mathrm{mmol} / \mathrm{L}$ sodium citrate buffer $\mathrm{pH} 6.0$ for 10 minutes. Nonspecific antibody binding in cells and slides was blocked with blocking buffer (0.2\% Triton X-100, 5\% normal donkey serum, and $5 \%$ nonfat milk in Tris-buffered saline) for 1 hour at room temperature before overnight incubation with affinity-purified specific primary antibodies (rabbit anti-human MMP-9, mouse anti-nonhematopoietic vimentin, mouse anti-human Ki-67, goat anti-PECAM-1 antibody) in blocking buffer at $4^{\circ} \mathrm{C}$. Cells and human GBM sections were incubated with alkaline phosphatase-conjugated secondary antibody (Jackson ImmunoResearch) diluted (1: 5000 ) in the blocking buffer for 1 hour at room temperature. The signals for MMP-9 expression in U1242 MG cells, TLs, and GBM patient specimens were detected by adding Fast-Red (Sigma). Purified IgGs from rabbit were used as negative controls. U1242 MG, U251 MG, U87 MG, scramble cells, CT30 and CT262 clone tumor slides were incubated with horseradish peroxidase-conjugated secondary antibodies using Vectastain ABC kit (Vector Laboratories, Burlingame, CA). Immunoreactivity was visualized by incubating the sections with 3, 3-diaminobenzidine tetrahydrochloride (DAKO Corp) to produce a brown precipitate. The slides were counterstained lightly with hematoxylin for viewing negatively stained cells.

\section{Collagen Type IV Invasion Assay}

The cell invasion assay was performed as described previously. ${ }^{36}$ Transwell insert with $8-\mu \mathrm{m}$ pores (Becton Dickinson, Boston, MA) was coated with $30 \mu$ l of different concentration of collagen type IV (Sigma, $0.25 \mathrm{mg} / \mathrm{ml}$, $0.125 \mathrm{mg} / \mathrm{ml}, 0.06 \mathrm{mg} / \mathrm{ml}, 0.03 \mathrm{mg} / \mathrm{ml}, 0.015 \mathrm{mg} / \mathrm{ml}$ ) and dried overnight. Non-collagen type IV-coated inserts were used as controls. Cell suspension $\left(0.5 \times 10^{5}\right.$ cells/ insert) in serum-free $\alpha$-Minimum Essential Medium was added to the upper chamber and the lower chamber contained $500 \mu \mathrm{l}$ of $\alpha$-Minimal Essential Medium media with $0.1 \%$ fetal bovine serum. After 24 -hour incubation, the noninvaded or nonmigrated cells in the upper chamber were gently scraped away, and adherent cells present on the lower surface of the insert were stained with $0.1 \%$ crystal violet solution and photographed. The invading cells were labeled with the brush tool in red color and manually counted with Photoshop software. A high number of cells migrated into the lower surface of the insert that was not coated with type IV collagen, but fewer cells invaded to the lower surface of the type IV collagen-coated insert. $0.25 \mathrm{mg} / \mathrm{ml}$ of type IV collagen showed the lowest number of invaded cells and was used for cell invasion assay in the presence or absence of GM6001 (20 $\mu \mathrm{mol} / \mathrm{L})$, MMP-9 function-blocking antibody $(25 \mu \mathrm{g} / \mathrm{ml})$, pro-MMP-9 $(5 \mathrm{ng} / \mathrm{ml})$, UO126 (10 $\mu \mathrm{mol} /$ L), LY294002 (10 $\mu \mathrm{mol} / \mathrm{L})$, or AG1478 (1 $\mu \mathrm{mol} / \mathrm{L})$ or/and EGF (25 ng/ml) for 24 hours. PBS, dimethyl sulfoxide, or mouse IgG was used as controls. Three independent experiments were performed. 


\section{Xenograft Mouse Model}

Adult male, nonobese diabetic, severe combined immunodeficient mice were purchased from Jackson Laboratories (Bar Harbor, Maine). The stereotactic techniques used to implant glioma cells have been described in our previous publication. ${ }^{39}$ Briefly, cells were grown in gelfoam for 9 days, and then one $\mathrm{mm}^{3}$ gelfoam (about $4 \times$ $10^{5}$ cells) was implanted in the right striatum of the mouse (five animals/each group). The mice were maintained according to the University of Virginia Animal Care and Use Committee protocols and checked regularly for postoperative neurological deficits. The tumor-bearing animals were imaged with magnetic resonance imaging 5 weeks postimplantation and sacrificed 6 weeks postimplantation. The brains were fixed in $10 \%$ zinc-formalin and processed for paraffin embedding. Tissue sections were stained by H\&E and by immunohistochemistry. All brain tumor sections were analyzed and reviewed by a neuropathologist, one of the authors (M.B.S.L.).

The section with the most extensive invasion and largest tumor mass was selected and photographed. The maximum distance between the edge of tumor mass and the infiltrating cells (single or cluster cells) in invading edge was measured by Image Pro 4.5 to be used as a criterion for in vivo invasiveness of glioblastoma cells. The mean of maximum distance $(n=15)$ was calculated from three different infiltrating single cells/clusters per animal and totally five different xenografts per group. The magnetic resonance imaging was performed and the tumor volume was calculated according to previous publication. ${ }^{40}$

\section{Stable Cloning of MMP-9 shRNA Lentiviral Transduction in U1242 MG Cells}

MMP-9 knock-down/out U1242 MG clones were generated by transduction of MMP-9 shRNA using SHVRS-NM 004994 MMP-9 MISSION shRNA lentiviral particles according to the manufacturer's instructions. The MISSION TRC shRNA target sequences for MMP-9 included (1)5'-CCGGCCACAACATCACCTATTGGATCTCGAGATCCAATAGGTGATGTTGTGGTTTTG-3', (2)5'-CCGGGCGGTGATTGACGACGCCTTTCTCGAGAAAGGCGTCGTCAATCACCCGCTTTTTG-3', (3)5'-CCGGCAGTACCGAGAGAAAGCCTATCTCGAGATAGGCTTTCTCTCGGTACTGTTTTTG-3', (4)5'-CCGGCGTTTCCATTCATCTTCCAACTCGAGTTGGAAGATGAATGGAAACTGTTTTTG-3'. MMP-9 shRNA-transducted U1242 MG cells and vector pLKO.1-scramble RNA-infected U1242 MG cells were selected with puromycin $(1.5 \mu \mathrm{g} / \mathrm{ml})$. After 3 weeks of shRNA or scramble RNA transduction, single clones were screened and characterized for the expression of MMP-9 mRNA and protein by RT-PCR, real time PCR, zymography, and Western blot.

\section{Cell Proliferation Assay}

DNA synthesis as a marker for cellular proliferation was measured by bromodeoxyuridine (BrdU) incorporation using the Cell Proliferation enzyme-linked immunosorbent assay, BrdU (colorimetric) (Roche, Mannheim, Germany) based on incorporation of BrdU into newly synthesized DNA and antibody-mediated detection of BrdU in DNA. Cells in $10 \%$ fetal bovine serum media were seeded in 96-well tissue culture plates at a density of $1.5 \times 10^{3}$ cells/well for 8 days. According to the manufacturer's instructions, BrdU was added for 24 hours, and then cells were fixed for 30 minutes and DNA was denatured with an ethanolic solution provided by the manufacturer, followed by incubation with BrdU antibody (90 minutes, $25^{\circ} \mathrm{C}$ ). Immune complexes were detected using tetramethylbenzidine for 10 minutes, and absorption was measured at $450 \mathrm{~nm}$ in an enzyme-linked immunosorbent assay reader (MRX II; Dynex, Frankfurt, Germany).

\section{Cell Motility Assay}

Coverslips in dishes were coated with $50 \mu \mathrm{g} / \mathrm{ml}$ poly-Llysine (Sigma). Two hours later, the coverslip dishes were washed with $\alpha$-Minimum Essential Medium, trypsinized cells were added at 1000 to 1500 cells per $\mathrm{cm}^{2}$, and cells were allowed to grow to $40 \%$ confluency. The next day, medium was exchanged with L-15 media (Sigma) containing $0.3 \%$ bovine serum albumin, $0.3 \mathrm{mmol} / \mathrm{L} \mathrm{Na}$ pyruvate, and $5.5 \mathrm{mmol} / \mathrm{L}(0.1 \%)$ glucose and the dish was placed in a microincubator (Harvard Apparatus PDMI-2, Holliston, MA) on an inverted microscope. After 1 hour, cells were imaged at 5 minutes intervals over 2 hours using an inverted microscope (Zeiss Axiovert 100TV) and a digital camera (Hamamatsu C4742-95-12NRB) with electronic shutters (Ludl Electronic Products Ltd., Hawthorne, NY) connected to a computer with tracking and imaging software (SimplePCl software, Compix, Inc., Cranberry Twp, PA). A minimum of 15 cells was tracked with SimplePCl tracking and imaging software (Compix) through the series of images to give a total curvilinear distance and velocity for each cell.

\section{Trypan Blue Staining and Cell Counting}

Cells were plated in 96-well cell-culture plates $\left(1.5 \times 10^{3}\right.$ cells/well) in $10 \%$ serum medium and incubated at $37^{\circ} \mathrm{C}$ for 1 to 7 days. Sequentially, cells were released from the plate with $0.05 \%$ trypsin-EDTA (30 to $60 \mu \mathrm{l} /$ well) and 10\% serum medium was added to stop the trypsin activity (20 to $40 \mu \mathrm{l} /$ well) and $0.4 \% \mathrm{w} / \mathrm{v}$ Trypan blue (Sigma) was added (1:5) for 5 minutes. For each experiment, cells were counted two times per well using a hemacytometer. Stained cells were counted as dead cells and unstained cells were counted as viable cells.

\section{Stable Expression of Dominant-Negative Ras in U1242 MG Cells}

U1242 MG cells were transfected with $5 \mu \mathrm{g} / \mathrm{ml}$ of RasN17 or with empty vector by incubation for 6 hours with PolyFect Transfection Reagent (10 $\mu \mathrm{l})$ according to manufacturer's instruction. The cells were selected in media con- 
taining G418 (400 $\mu \mathrm{g} / \mathrm{ml})$. After 3 weeks, the mixed cultures were screened for Ras expression and singlecell clones were screened and characterized for overexpression of RasN17.

\section{Soft Agar Colony Formation}

A total of $5 \times 10^{3}$ cells per well were seeded in a 24-well plate in $0.3 \mathrm{ml}$ of $0.4 \%$ agar medium over $0.5 \mathrm{ml}$ of $0.8 \%$ agar medium. EGF or kinase inhibitors were added to the top agar at the desired concentration. Liquid medium (1 $\mathrm{ml}$ ) was added the day after plating the top agar. After 22 days, pictures of colonies were taken with microscopes at $\times 50$ or $1.5 \times 7$ magnifications. The area of colony was determined with ImagePro 4.5 and Photoshop software. The data are given as means \pm SE of three independent wells.

\section{Densitometric Analysis}

MMP-9, PECAM-1, or Ki-67 immunostainings were quantified using Imag-Pro Plus software. Four photos were taken from each group with a Nikon microscope equipped with a CCD camera. Count/Size was selected within the 'measure' menu. An appropriate color threshold (RGB) was chosen (For Ki-67 staining, R: 24-157, G: 15-120, B: 9-97; for PECAM-1 staining, R: 0-178, G: 0-130, B: 1-89; for MMP-9 staining, R: 29-183, G: 24-138, B: 18$100)$ to include the staining of signal. The area of tumors (for MMP-9 and Ki-67 staining) or whole high power field (for PECAM-1 staining) was manually selected using irregular area of interest. Density (mean) was obtained and equal to optical density divided by the selected area, which represents the average optical density of an object. The value of density (mean) from each group was then used for subsequent statistical analysis.

\section{Statistical Analyses}

Statistical differences were determined using one-way analysis of variance followed by Newman-Keuls Comparison or two-way analysis of variance from Prism GraphPad Software. Data were presented as the mean \pm SEM from at least triplicate experiments. $P$ value equal or less than 0.05 is considered to be significant.

\section{Results}

\section{High MMP-9 Expression and Gelatinolytic Activity Are Associated with in Vitro Invasiveness of Human GBM U1242 MG Cells}

To determine MMP-9 expression in GBM patient specimens, we compared MMP-9 expression and gelatinolytic activity between GBM and TLs by RT-PCR, Western blot, gelatin zymography, and immunohistochemistry. As shown in Figure 1A, top and middle panel, the MMP-9 expression of mRNA transcript and protein was higher in GBM specimens $(n=10)$ than TLs $(n=10)$. The $\beta$-actin and $\alpha$-tubulin were used as loading controls for RT-PCR and Western blot, respectively. Similarly, GBM patient specimens showed higher gelatinolytic activity of MMP-9, as compared with TLs (Figure 1A, bottom panel). Immunohistochemistry analysis revealed that MMP-9 protein was present in the infiltrating tumor cells and tumor mass of human GBM specimens $(n=10)$ but not in TLs $(n=3)$ (Figure 1B, black arrows show the tumor cells), normal rabbit IgG was used as a control. Next we compared the expression of MMP-9, MMP-2, and urokinase plasminogen activator (UPA) in GBM cell lines U87 MG, U1242 MG, and U251 MG cells by RT-PCR, gelatin, and plasminogen/fibrinogen zymography. U1242 MG cells expressed high levels of MMP-9 mRNA transcript (Figure $1 \mathrm{C}$, top panel) and strong $92 \mathrm{kDa}$ proenzyme MMP-9, as well as weak $84 \mathrm{kDa}$ gelatinolytic activity (Figure 1C, bottom panel). The level of MMP-2 gelatinolytic activity was similar in NHA, U87 MG, U1242 MG, and U251 MG cells (Figure $1 \mathrm{C}$, bottom panel). In addition, uPA activity was similar in U87 MG, U1242 MG, and U251 MG cells, but higher than those in NHA cells (data not shown). U87 MG and U251 MG cells also showed low level of MMP-9 mRNA (Figure 1C, top panel) and weak 82kDa (U87 MG cells) and 84 kDa (U87 MG and U251 MG cells) gelatinoIytic activity (Figure 1C, bottom panel). To determine whether a high level of MMP-9 expression correlates with cell invasion, a type IV collagen invasion assay was performed. Interestingly, the invasiveness in high MMP-9 expressing U1242 MG cells showed 5- and 40-fold increases compared with low MMP-9 expressing U251 MG and U87 MG (Figure 1D, top panel, $P<0.01$ ), respectively. To further determine whether proteolysis of high 92 kDa proenzyme MMP-9 mediates U1242 MG cell invasion in vitro, we compared the gelatinolytic activity in conditioned media from U87 MG, U1242 MG, and U251 MG cell invasive inserts. Our results showed stronger active $82 \mathrm{kDa}$ and $70 \mathrm{kDa}$ bands in conditioned media of U1242 MG cells, and weaker 82 kDa band in conditioned media of U251 MG cells and U87 MG cells (Figure 1D, bottom panel). To confirm that MMP-9 is functionally active in cell invasiveness in vitro, we used a general MMP inhibitor GM6001 and MMP-9 function-blocking antibody to block U1242 MG cell invasion in vitro. GM6001 or MMP-9 function-blocking antibody alone and a combination of them significantly reduced the invasion of U1242 MG cells by $50.6 \%$ or $46.5 \%$ and $59.7 \%$, respectively (Figure 1E, $P<0.01$ ). These data demonstrate that high functionally active MMP-9-mediated proteolytic activity plays an important role in 1242 MG cell invasion in vitro.

\section{High MMP-9 Expression Is Associated with Extensive Invasion of U1242 MG Tumors in Xenograft Mouse Model}

To explore whether high MMP-9-expressing U1242 MG cells exhibit a high degree of tumor cell infiltration into surrounding brain tissues, we implanted U1242 MG, U251 MG, and U87 MG cells into mouse brain. We compared the histopathology of U1242 MG, U251 MG, and U87 MG xenograft models, the latter two xenograft mod- 


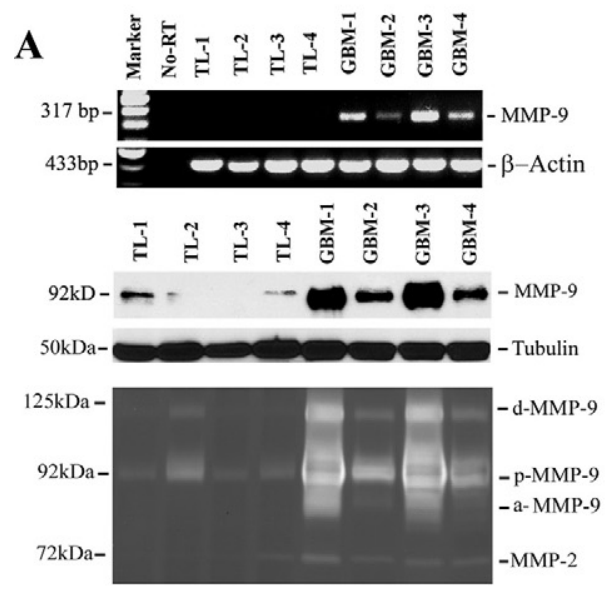

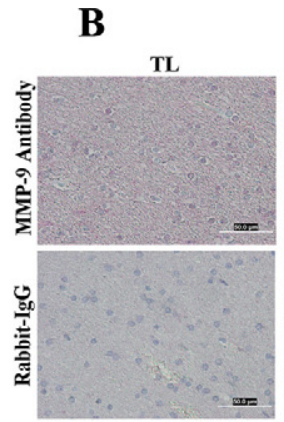

D

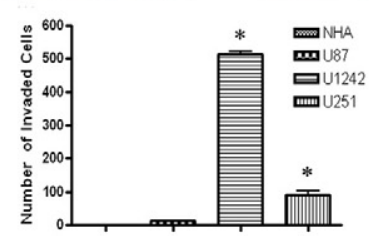

Mean \pm SEM $0 \pm 0 \quad 11.3 \pm 1.9 \quad 514 \pm 7.3 \quad 90.7 \pm 10.5$

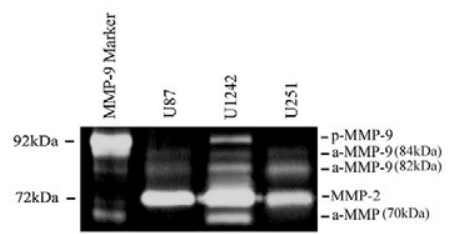

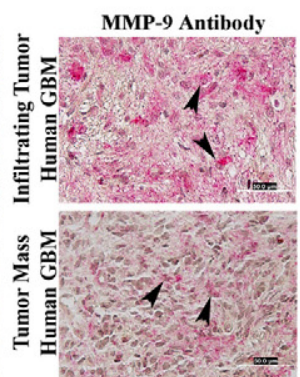

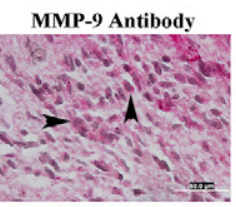

Rabbit-IgG

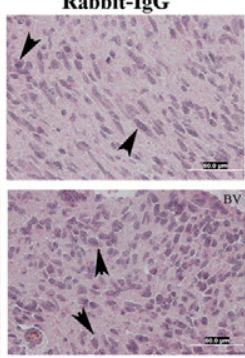

$\mathbf{E}$
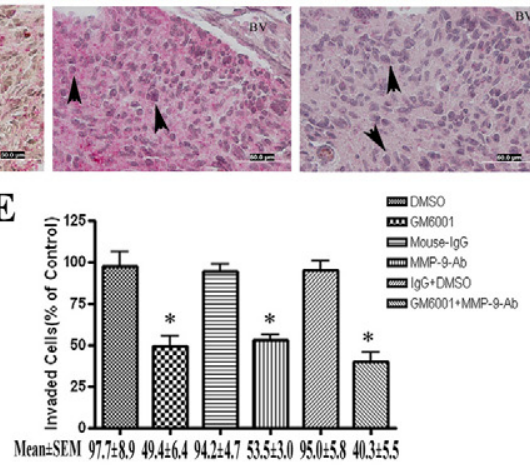

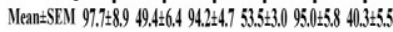

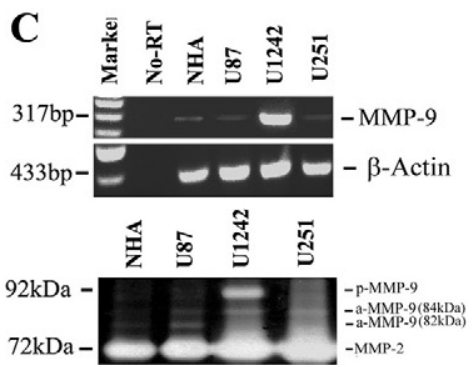

Figure 1. Expression of MMP-9 in GBM patient specimens and human GBM cell lines. A: Expression of MMP-9 mRNA (top panel, RT-PCR), protein (middle panel, Western blot), and gelatinolytic activity (bottom, zymography) in GBM patient specimens and nonneoplastic temporal lobes (TLs). $\beta$-actin and tubulin were used as loading controls for RT-PCR and Western blot, respectively. Equal amount of proteins (30 $\mu \mathrm{g} /$ lane) was loaded. d-MMP-9, dimeric MMP-9; p-MMP-9, pro-MMP-9; a-MMP-9, active MMP-9. B: Localization of MMP-9 showed by immunohistochemistry in TL and GBM patient specimens. Red color indicates MMP-9 immunoreactive signals. Black arrows indicate tumor cells. The normal rabbit IgG was used as control. The pictures were taken at $\times 400$ magnification. BV, blood vessel. C: MMP-9 mRNA (top panel, RT-PCR) and gelatinolytic activity (bottom panel) in NHA (normal human astrocytes), U87 MG, U1242 MG, and U251 MG cells. $\beta$-actin was used as loading control. D: Comparison of NHA, U87 MG, U1242 MG, and U251 MG cell invasion in vitro (top panel). Data shown are the mean \pm SEM values from three separate experiments for each group. Bottom panel: comparison of MMP-9 gelatinolytic activity in conditioned media from the transwells of U87 MG, U1242 MG, and U251 MG cell invasion (bottom panel). p-MMP-9, pro-MMP-9; a-MMP-9, active MMP-9. E: Broad spectrum MMP inhibitor and MMP-9 function-blocking antibody inhibited the cell invasion of U1242 MG cells. GM6001: Broad spectrum MMP inhibitor, $20 \mu$ mol/L. MMP-9 Ab: MMP-9 antibody, $25 \mu \mathrm{g} / \mathrm{ml}$. Data shown are the mean \pm SEM values from three separate experiments for each group. ${ }^{*} P<0.01$.

els have been commonly used for developing novel therapies for GBM. The overall morphological appearance of the three xenograft tumors was shown in Figure 2, A, B, and $\mathrm{C}$. Vimentin immunostaining was performed to show more clearly the invasive pattern of xenograft tumors. The invasion of U1242 MG xenograft tumor in NOD SCID mice was characterized by widespread tumor cell infiltration within the non-neoplastic brain parenchyma (Figure 2A, black arrows show the invasive edge of tumor). However, tumor invasion in U251 MG and U87 MG xenograft model was not as dramatically extensive as that in U1242 MG xenograft model (Figure 2, B and C, black arrow show the edge of tumor mass), although U87 xenograft formed larger tumor mass. The mean $(n=15)$ maximal distance between the edge of tumor mass and infiltrating cells in U1242 MG xenograft model was $1381.24 \pm 98.4 \mu \mathrm{m}$ and significantly greater than those in U87 MG (123.93 \pm $13.86 \mu \mathrm{m})$ or U251 MG (252.07 $\pm 24.15 \mu \mathrm{m})$ xenograft model $(P<0.01)$ (Figure 2D). All tumor cells were identified by their strongly acidophilic cytoplasm, a high nucleus to cytoplasm ratio, nuclear and cytoplasmic abnormal morphology, and their pleomorphism.

More importantly, U1242 MG xenograft model displayed abundant single cell (Figure 2E, pointed by black arrows), cluster cell (Figure 2F, pointed by black arrows), perivascular cell (Figure 2G, pointed by black arrow), and subpial cell (Figure $2 \mathrm{H}$, pointed by black arrow) infiltrations. Perivascular and subpial tumor cell infiltration either by single cell spread or by perivascular spread mimic the so-called "secondary structures of Scherer" that is typically seen in human GBM. ${ }^{41,42}$

PECAM- $1(\text { CD31 })^{43}$ is generally used in the evaluation of angiogenesis. Even though it not only reacts with newly formed vessels but also with normal vessels just entrapped within tumor tissues, we still can assess hypervascularity by comparing the density of PECAM- 1 staining between the tumors and normal brain tissues. As shown in Figure 3A-3G, PECAM-1 immunostaining demonstrated that the microvessels (pointed by black arrows) within infiltrating tumor beds in invasive U1242 MG xenograft were more tortuous and larger (Figure 3A) than those in the tumor core (Figure 3B), the brain adjacent to tumor (Figure 3C) and contralateral normal brain (Figure 3D) in invasive U1242 MG xenograft, as well as the tumor core and the brain adjacent to tumor in noninvasive U87 MG xenograft (Figure 3, E and F, respectively). The vascular density within the infiltrating tumor beds in invasive U1242 MG xenograft was dramatically higher than those in tumor core, at the infiltrating tumor-brain interface and normal brain in invasive U1242 MG xenograft and nonin- 


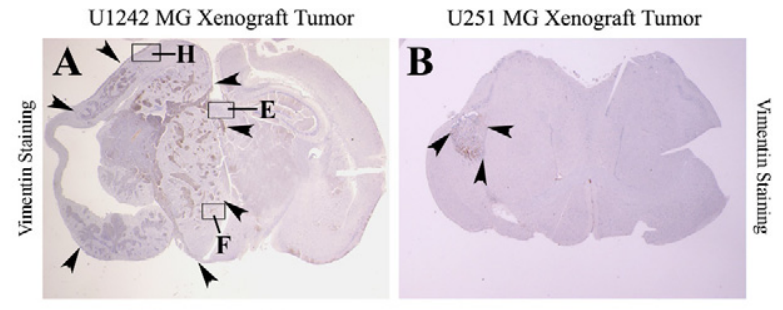

U87 MG Xenograft Tumor
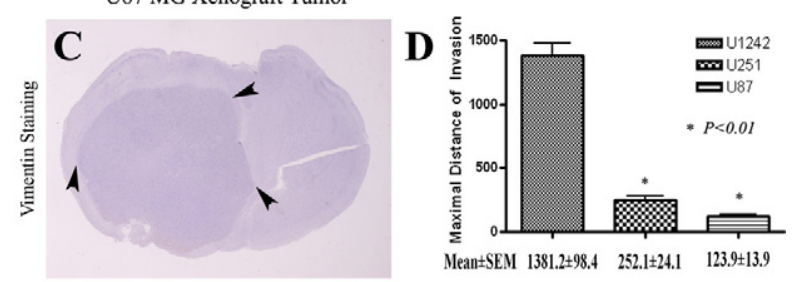

U1242 MG Xenograft Tumor

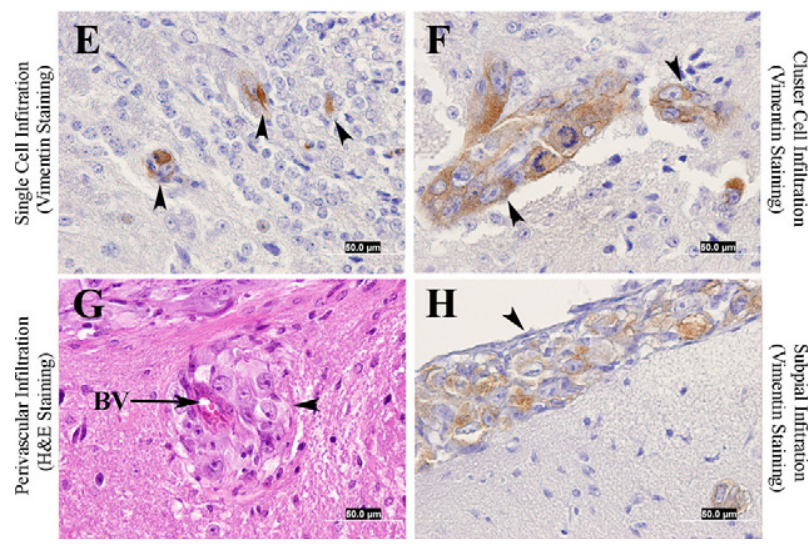

Figure 2. Histopathological comparison among U1242 MG, U251MG, and U87 MG human GBM xenografts in NOD SCID mice. The mice were sacrificed 6 weeks postimplantation. Sections are representative of tumors from five animals per group. A: Extensive infiltration of U1242 MG xenograft tumor in mouse brain. The FFPE sections $(5 \mu \mathrm{m})$ of xenograft tumor in NOD SCID mice were stained with vimentin by immunohistochemistry to show the invasive edge of tumor. Extensive neoplastic cellular infiltration into surrounding normal brain tissue is clearly seen (black arrows show the edge of invading tumor). The picture is $\times 8$ magnification. Boxed areas $\mathbf{E}, \mathbf{F}$, and $\mathbf{H}$ indicate the invasive edge of U1242 MG xenograft tumors and magnified pictures are shown in Figures 2, E, F, and $\mathbf{H}$ below. $\mathbf{B}$ and $\mathbf{C}$ : Limited tumor infiltrations of U251 and U87 MG xenograft tumors in mouse brains. The FFPE sections $(5 \mu \mathrm{m})$ of xenograft tumors in NOD SCID mice were stained with vimentin by immunohistochemistry to show the edge of tumor mass. Black arrows indicate the edge of tumor mass. The pictures are $\times 8$ magnification. D: Maximal invasive distance of U1242 MG, U251 MG, and U87 MG xenografts in mouse brains. $n=15$. E: Single cell infiltration (pointed by black arrows) at the invasive edge from boxed area $\mathbf{E}$ in Figure $2 \mathbf{A}$. The picture is $\times 400$ magnification. F: Cluster cell infiltration (pointed by black arrows) at the invasive edge from boxed area $\mathbf{F}$ in Figure $2 \mathbf{A}$. The picture is $\times 400$ magnification. G: The section of U1242 MG xenograft tumor was stained with H\&E staining to show perivascular infiltration (arrow indicates perivascular cells). BV, blood vessel. The picture is $\times 400$ magnification. $\mathbf{H}$ : Subpial cell infiltrations (pointed by black arrows) at the invasive edge from boxed area $\mathbf{H}$ in Figure $2 \mathrm{~A}$. The picture is $\times 400$ magnification.

vasive U87 MG xenograft (Figure 3G, $P<0.01$ ). These results indicate that infiltrating tumor cells may induce microvascular proliferation (hypervascularity). Geographic necrosis was also found in our U1242 MG xenograft model (Figure $3 \mathrm{H}$ ).

To further confirm the association between high MMP-9 expression and glioma cell extensive infiltration in the brain, we performed immunohistochemistry by using a MMP-9 antibody that detects full length and cleaved
MMP-9 to compare MMP-9 expression in vivo in U1242 MG, U251 MG, and U87 MG xenograft tumors. As shown in Figure 3, $1-0$, strong positive MMP-9 signals were detected in U1242 MG tumor cells, especially in infiltrating single cells (Figure 3l, pointed by black arrows), perivascular cells (Figure 3J, pointed by black arrow), cluster cells (Figure 3, I and K, pointed by white arrows), subpial cells (Figure 3K, pointed by black arrow). MMP-9 expression in U1242 MG tumor mass (Figure 3L, pointed by black arrow) was weaker than those in U1242 MG infiltrating single, cluster, perivascular, and subpial cells (Figure 30, $P<0.01$ ) but higher than those in U251 MG and U87 MG tumor masses (Figure 3, M, N, and O, pointed by black arrows, $P<0.01)$. Our results imply that high level of MMP-9 in U1242 MG tumors may be associated with the extensive infiltration and microvascular proliferation.

\section{shRNA Silencing of MMP-9 Expression in U1242 MG Cell Inhibits Invasion in Vitro and in Vivo}

To directly determine the role of MMP-9 in the extensive invasion of U1242 MG xenograft tumor in NOD SCID mice, lentiviral shRNA designed specifically targeting MMP-9 mRNA was infected into high MMP-9-expressing U1242 MG cells. Multiple single-cell subclones were screened and characterized for MMP-9 deficiency. Nontarget scramble shRNA was used as a control. Real-time PCR showed that MMP-9 mRNA was silenced by $92 \%$ and $96 \%$ in MMP-9 shRNA clones CT30 and CT262, respectively, compared with scramble cells (Figure 4, A, top panel). Secreted MMP-9 protein expression and 92kDa MMP-9 gelatinolytic activity (Figure 4A, middle panel) in CT30 and CT262 clones were dramatically decreased compared with scramble cells. The MMP-9 mRNA transcripts, gelatinolytic activity, and invasion were not significantly altered in scramble control cells compared with wild-type U1242 MG cells (data not shown). In the collagen type IV-coated invasion assay, CT30 and CT262 clones were much less invasive and showed $57.8 \%$ and $87.4 \%$ reduction of invasion, respectively, when compared with scramble cells (Figure 4A, bottom panel, $P<0.01$ ). Our previous studies demonstrated that U1242 MG cells highly expressed both UPA and MMP-9, as well as UPA-mediated $92 \mathrm{kDa}$ proenzyme MMP-9 activation promotes U1242 MG cell invasion in vitro. ${ }^{22}$ To directly link the MMP-9 proteolytic activity to increased U1242 MG cell invasiveness, functional rescue experiments were performed by an addition of exogenous pro-MMP-9 enzyme (5 ng/ml) to CT30 and CT262 cells. The result showed that the invasive ability of CT30 and CT262 cells increased by 0.40 and 2.93 folds, $(P<$ 0.05 and $P<0.01$, respectively) (Figure 4A, bottom panel), indicating MMP-9-mediated proteolytic activity play a functional important role in 1242 MG cell invasion in vitro.

To confirm our in vitro invasion data to an in vivo situation, the MMP-9-silenced clones and scramble control cells were intracranially implanted into NOD SCID mice. 

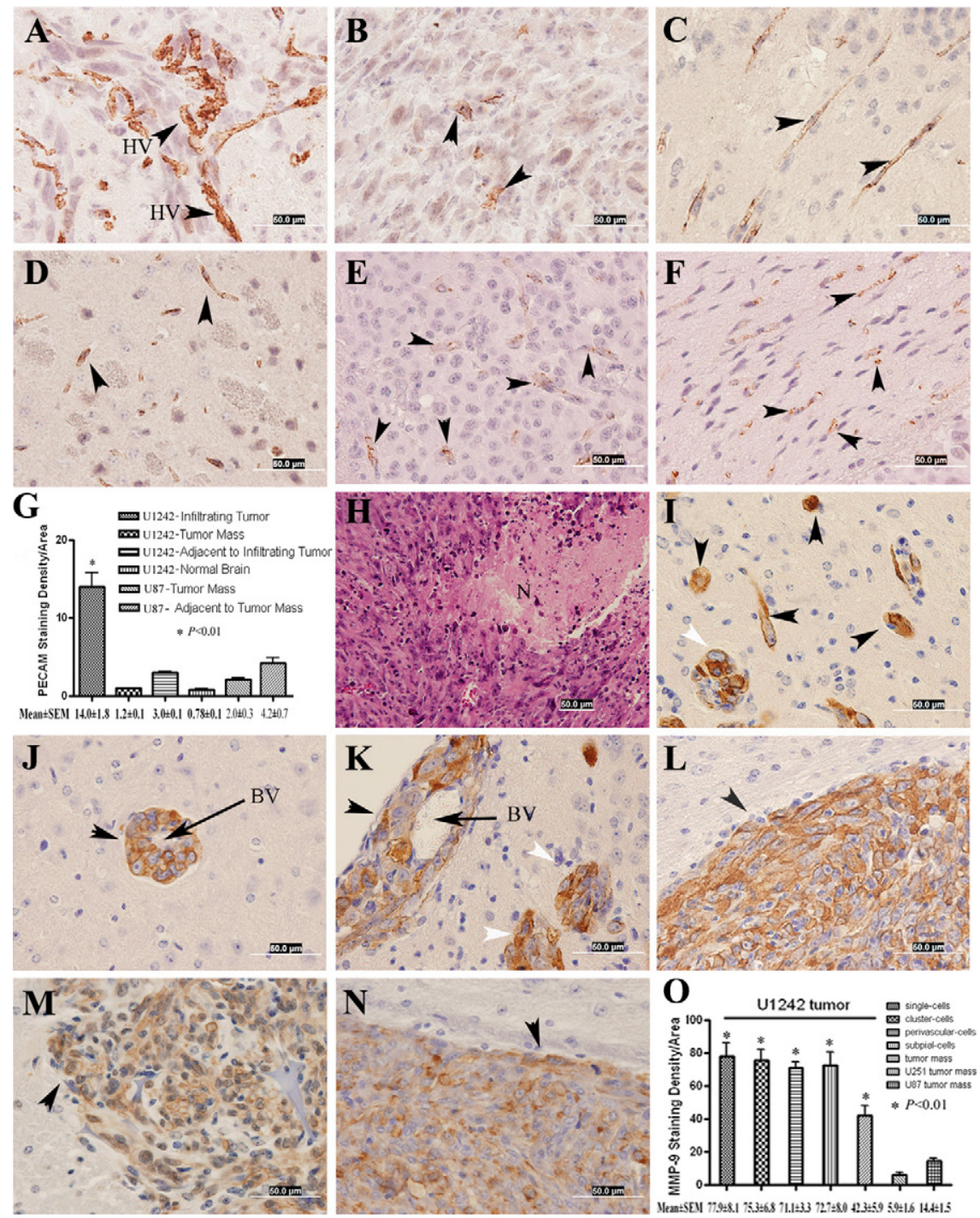

Figure 3. PECAM-1 and MMP-9 immunostaining in U1242 MG, U251, and U87 MG xenograft tumor sections. A-D: The sections of U1242 MG xenograft tumors were immunostained with PECAM-1 to show microvessel density in infiltrating tumor beds (A, HV, hypervascularity), in tumor mass (B), brain adjacent to infiltrating tumor $(\mathbf{C})$ and contra-lateral normal brain (D). Brown color indicates PECAM-1 positive staining. The pictures are $\times 400$ magnification. The black arrows indicate microvessels. E-F: The sections of U87 MG xenograft tumors were immunostained with PECAM-1 to show vessel density in tumor mass (E) and brain adjacent to tumor mass (F) Brown color indicates PECAM-1 positive staining. The pictures are $\times 400$ magnification. The black arrows indicate blood microvessels. G Densitometric quantitative analysis of PECAM-1 staining in the U1242 MG and U87 MG xenografts. Data represents four or six different staining fields under $\times 400$ magnification. $\mathbf{H}: \mathrm{H} \& \mathrm{E}$ staining of geographic necrosis in U1242 MG xenograft. The picture is $\times 200$ magnification. $\mathrm{N}$, necrosis. I-L: The sections in U1242 MG xenograft tumor were stained with MMP-9 antibody to show MMP-9 expressions in single cells (I) indicated by black arrows, in cluster cells (I and $\mathbf{K}$ ) indicated by white arrows, in perivascular cells ( $\mathbf{J}$ ) indicated by black arrow, in subpial cells $(\mathbf{K})$ indicated by black arrow, and in tumor mass (L) indicated by black arrow. Brown color indicates MMP-9 positive staining. The pictures are $\times 400$ magnification. BV, blood vessel. $\mathbf{M}$ and $\mathbf{N}$ : The sections of U251 and U87 MG xenograft tumors, respectively, were stained with MMP-9 antibody. The pictures are $\times 400$ magnification. The black arrows point to tumor mass. O: Densitometric quantitative analysis of MMP-9 staining in the U1242 MG, U251MG, and U87 MG xenograft tumors. Data shown are the mean \pm SEM values from four or six different fields for each group.

Each group had a total of 5 mice and each mouse received approximately $4 \times 10^{5}$ cells. Five weeks post implantation, the tumors were imaged with magnetic resonance imaging and the result showed large tumors covering $1 / 2$ of the hemisphere in mice that were implanted with scramble cells, whereas mice that received shMMP-9 CT30 and CT262 clones had smaller and wellcircumscribed tumors (Figure 4B, top panel, white arrows show the tumor edge). The mean tumor volumes of CT30 and CT262 clones were significantly decreased by approximately $75 \%$, when compared with scramble control (Figure 4B, bottom panel, $P<0.01$ ).

At the end of the study, the mice were sacrificed and the FFPE brain sections were immunostained with vimentin. Similar to the U1242 MG tumors, the mice implanted with scramble cells developed extensive and invasive tumors within the brain parenchyma (Figure 5A, black arrows show the invading edge of tumor). In contrast, mice implanted with the CT30 clone showed well circumscribed tumor, lacking extensive infiltrating phenotype (Figure 5B, black arrows show the edge of tumor mass). Mice implanted with the CT262 clone showed no tumor formation or very small tumor mass formation (Figure 5C, black arrows show the edge of tumor mass). The mean $(n=15)$ maximal distance between the tumor mass and infiltrating cells in scramble control xenograft model was $1487 \pm 69.7 \mu \mathrm{m}$ and significantly greater than those in CT30 clone xenograft model $(340 \pm 23.1 \mu \mathrm{m}, P<0.01)$ or CT262 clone xenograft model $(79.3 \pm 12.0 \mu \mathrm{m}, P<$ 0.01) (Figure 5D).

Similarly, scramble xenograft model also displayed abundant single cell (Figure 5E, pointed by black arrows), cluster cell (Figure 5, E and G, pointed by white arrows), perivascular cell (Figure 5F, pointed by black arrows), and subpial cell (Figure 5G, pointed by black arrows) infiltrations. Geographic necrosis was also seen in scramble xenograft model (data not shown).

Because only the CT30 clone xenograft formed tumor mass, whereas the CT262 clone xenograft showed very small tumor mass formation, we compared MMP-9 immunostaining between scramble and СТ30 clone xenograft tumors. The results showed strong positive MMP-9 signal in scramble control tumor cells, especially in infiltrating single cells (Figure 5E, pointed by black arrows), perivas- 


\section{A}
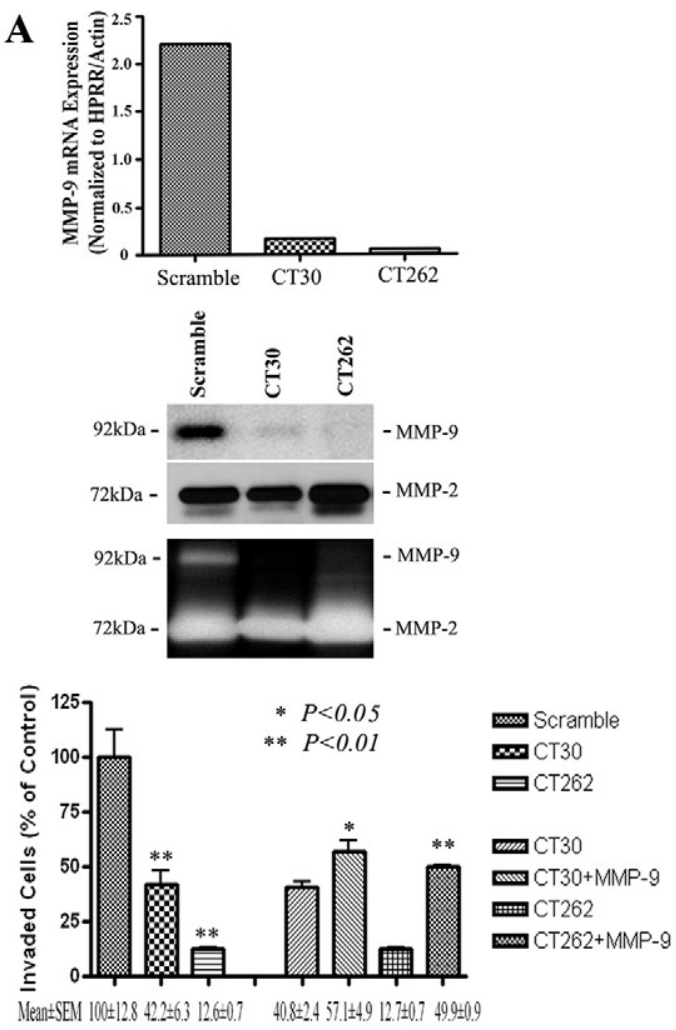

B
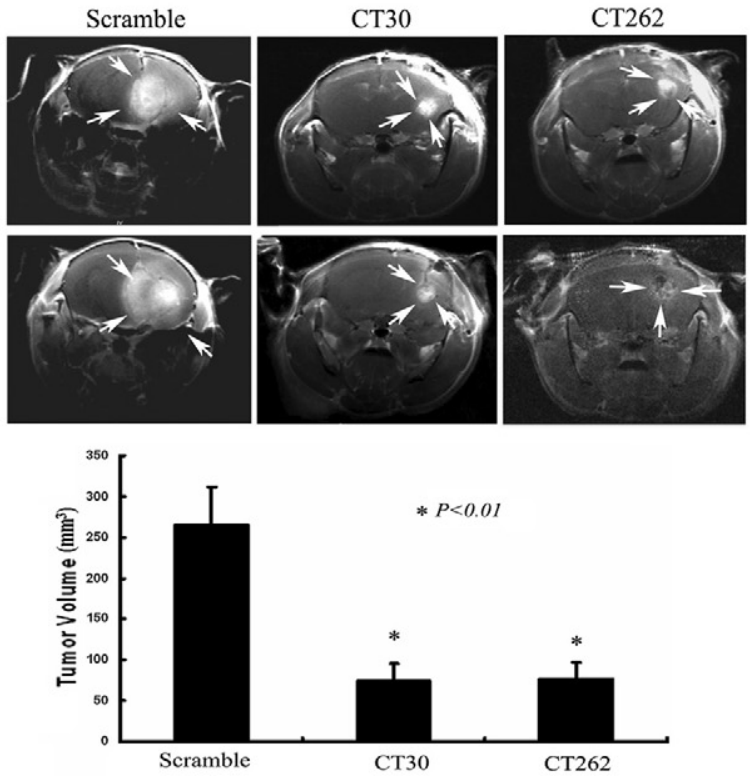

Figure 4. Stable silencing of MMP-9 by shRNA in U1242 MG cells. A: Expression of MMP-9 MRNA and protein in scramble, and MMP-9 silencing clones (CT30 and CT262) as determined by real-time PCR (top panel), Western blot and zymography (middle panel). MMP-9 shRNA significantly decrease $\mathrm{U} 1242$ cell invasion in vitro, this inhibition was rescued by adding purified recombinant MMP-9 $(5 \mathrm{ng} / \mathrm{ml})$, especially in CT262 clone (bottom panel). HPRR: histidine-containing phosphocarrier protein-response regulator. Data shown are the mean \pm SEM values from three separate experiments for each group. Scramble were U1242 MG cells transfected with vector pLKO.1-scramble. CT30 and CT262 cells were single-cell cloned from MMP-9 shRNA transfected U1242 MG cells. B: Magnetic resonance image and tumor volume analysis of scramble, CT30, and CT262 human xenografts in NOD SCID mouse brain. Cultured scramble, CT30, and CT262 cells in gelfoam were implanted in the brains of NOD-SCID mice. The mice were scanned by magnetic resonance imaging 5 weeks postimplantation (top panel). White arrows indicate tumor borders. Bar graph of the tumor volume $\left(\mathrm{mm}^{3}\right)$ of scramble, CT30, and CT262 clones (bottom panel). Data shown are the mean \pm SEM values from five animals for each group.
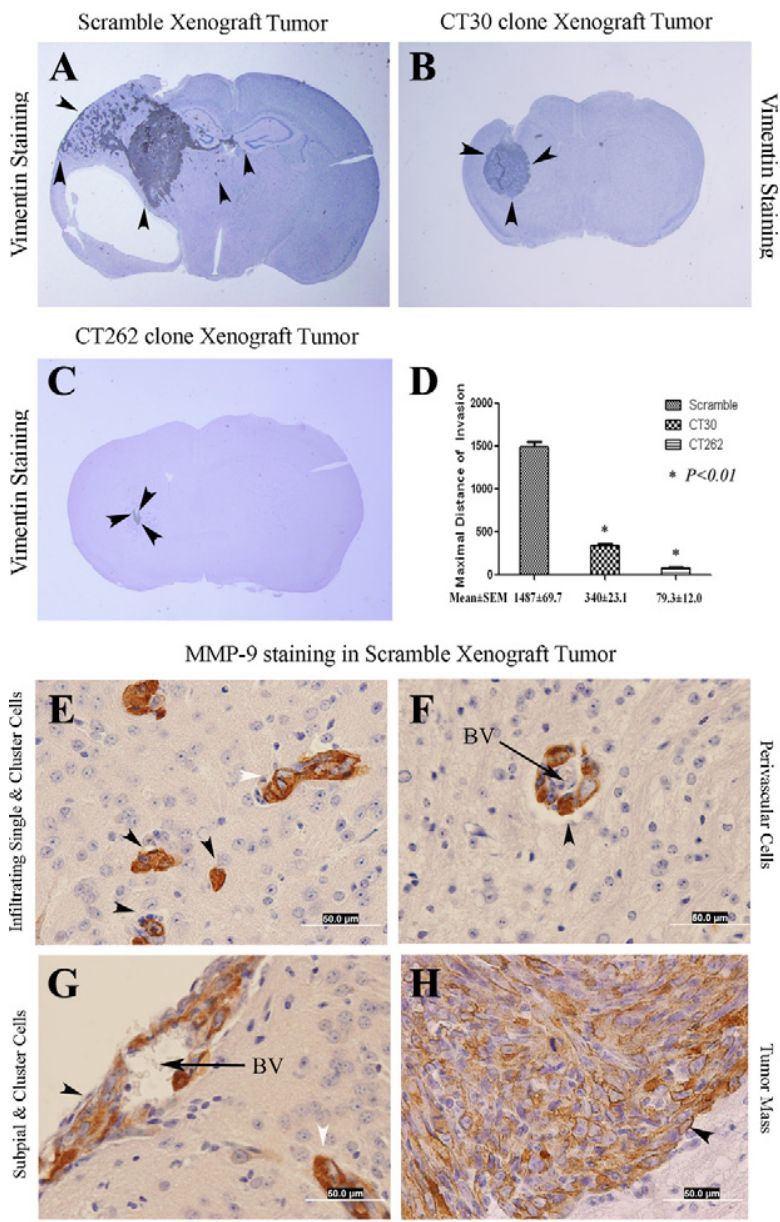

MMP-9 staining in CT30 Xenograft Tumor
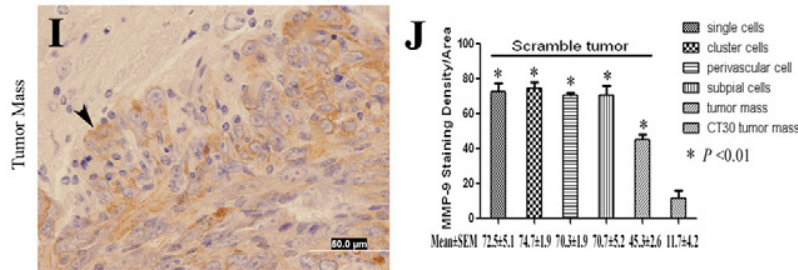

Figure 5. Histopathological comparison among scramble, CT30, and CT262 xenografts in NOD SCID mice. The mice were sacrificed 6 weeks postimplantation. Sections are representative of tumors from five animals per group. A: Extensive infiltration of scramble xenograft tumor in mouse brain. The section of xenograft tumor was stained with vimentin to show the invasive edge of tumor. Neoplastic cellular extensive infiltration into surrounding nonneoplastic brain tissue is clearly seen (black arrows show the edge of invading tumor). The picture is $\times 8$ magnification. B-C: Limited tumor infiltrations of CT30 and CT262 xenograft tumors in mouse brains. The sections of xenograft tumor were stained with vimentin to show the edge of tumor mass pointed by black arrows. The pictures are $\times 8$ magnification. D: Maximal invasive distance of scramble, CT30, and CT262 xenografts in mouse brains. $n=15, \mathbf{E}-\mathbf{H}$ : The sections of scramble xenograft were stained with MMP-9 antibody. Brown color indicates MMP-9 positive staining. The black arrows indicate MMP-9 staining in single cells (E), in perivascular cells (F), in subpial cells $(\mathbf{G})$, in tumor mass $(\mathbf{H})$. The white arrows indicate MMP-9 staining in cluster cells $(\mathbf{E}, \mathbf{G})$. BV, blood vessel. The pictures are $\times 400$ magnification. I: The section of CT 30 xenograft was stained with MMP-9 antibody. Brown color indicates MMP-9 positive staining. The black arrow indicates MMP-9 staining in tumor mass. The pictures are $400 \mathrm{X}$ magnification. J: Densitometric quantitative analysis of MMP-9 staining in the scramble and CT30 xenograft tumors. Data shown are the mean \pm SEM values from four or six different fields for each group.

cular cells (Figure 5F, pointed by black arrow), cluster cells (Figure 5, E and G, pointed by white arrows), and subpial cells (Figure 5G, pointed by black arrow). However, MMP-9 signal in scramble tumor mass (Figure $5 \mathrm{H}$, 


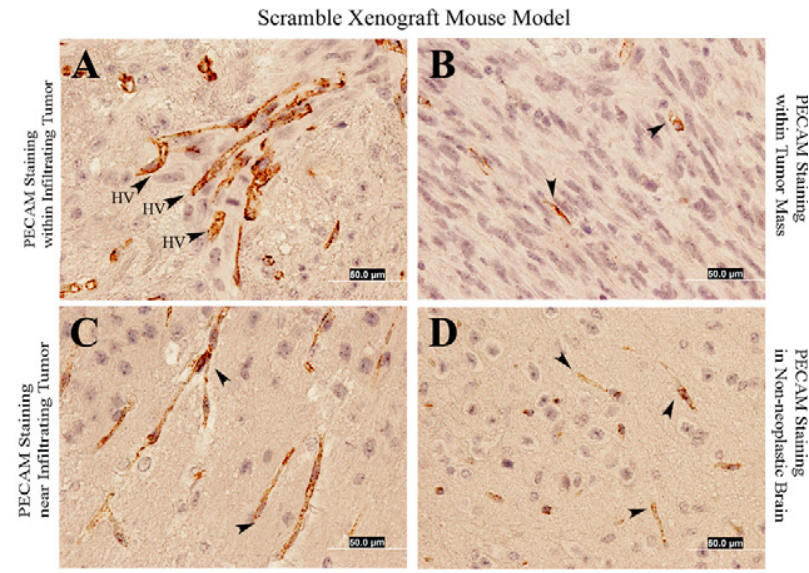

СT30 clone Xenograft Mouse Model
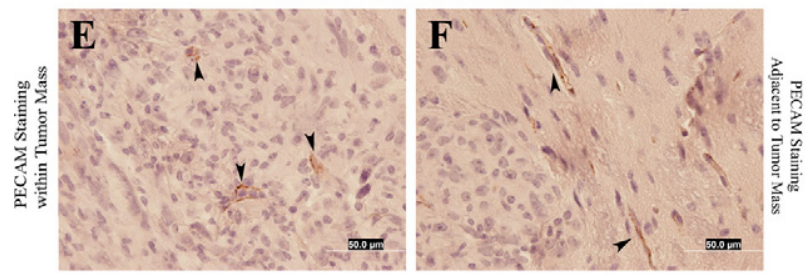

G

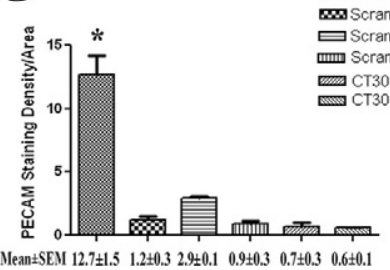

Figure 6. PECAM-1 staining in scramble and CT30 xenografts. The sections of scramble and CT30 xenograft tumors were immunostained with PECAM-1 to show microvessel density. Brown color indicates PECAM-1 positive staining. The pictures are $\times 400$ magnification. The black arrows indicate microvessels within infiltrating tumor beds in scramble xenograft (A, HV, hypervascularity), in tumor mass of scramble xenograft (B), brain adjacent to infiltrating tumor of scramble xenograft $(\mathbf{C})$, and contralateral normal brain of scramble xenograft (D), as well as in tumor mass of CT30 clone xenograft (E) and brain adjacent to tumor mass of CT30 clone xenograft (F). G: Densitometric quantitative analysis of PECAM-1 staining in the scramble and CT30 clone xenografts. Data represents four or six different staining fields under $\times 400$ magnification. ${ }^{*} P<0.01$.

pointed by black arrow) was weaker than that in scramble infiltrating single, cluster, perivascular, and subpial cells (Figure 5J, $P<0.01$ ), but still significantly higher than that in the CT30 clone tumor mass (Figure 5, I and J, pointed by black arrow, $P<0.01)$. The results clearly suggest that the high level of MMP-9 in U1242 MG cells contributes to extensive infiltrative invasion of U1242 MG xenograft tumor in NOD SCID mice.

Similarly, as shown in Figure 6, A-D, PECAM-1 immunostaining in scramble tumors displayed hypervascularity (pointed by black arrows) within the infiltrating tumor beds (Figure 6A), but not in tumor core (Figure 6B, black arrows show microvessels), brain adjacent to the infiltrating tumor (Figure 6C, black arrows show microvessels), and contralateral normal brain (Figure 6D, black arrows show microvessels). Hypervascularity was not observed in CT30 tumor core (Figure 6E, black arrows show microvessels) or brain adjacent to the tumor core (Figure $6 \mathrm{~F}$, black arrows show microvessels). The vascular den- sity within the infiltrating tumor beds in scramble xenograft was dramatically higher than those in the tumor core, at the infiltrating tumor-brain interface and normal brain in scramble xenograft and noninvasive CT30 xenograft (Figure 6G, $P<0.01$ ). These results demonstrate that the high level of MMP-9-associated infiltrating tumor induced the hypervascularity in U1242 MG xenograft.

\section{shRNA Silencing of MMP-9 Expression in U1242 MG Cells Inhibited Cell Motility and Cell Proliferation}

In addition to proteolytic activity, the ability of tumor cells to invade also depends on cell motility, proliferation, and survival. To assess the effect of down-regulation of MMP-9 on cell motility, proliferation, and death, a cell motility assay, cell proliferation assay, and trypan blue staining were performed. Our results demonstrated that the down-regulation of MMP-9 reduced the motility of CT30 and CT262 clones by $35.3 \%$ and $32.4 \%$, respectively, as compared with control scramble (Figure 7A). The number of dead cell showed no changes among the scramble control and shMMP-9 clones from days 3 to 8 (Figure 7B). The number of viable cells in CT30 and CT262 clones did not change during days 2 to 4 , but was significantly reduced by approximately $44.9 \%(P<0.01)$ and $63.6 \%(P<0.01)$ at day 8 , respectively, as compared with the scramble control cells (Figure 7C, left panel). Cell proliferation of CT30 and CT262 clones was also reduced by $27.4 \%(P<0.05)$ and $34.1 \%(P<0.01)$ at day 8 , respectively, compared with scramble cells (Figure 7C, right panel). To extend our in vitro proliferative data to an in vivo situation, the immunohistochemistry staining for Ki-67 was performed. The results showed strong Ki-67 staining in single cells (Figure 7D, pointed by black arrows), cluster cells (Figure 7E, pointed by black arrows), subpial cells (Figure 7F, pointed by black arrows), perivascular cells (Figure $7 \mathrm{G}$, pointed by black arrows), and the edge of tumor mass (Figure $7 \mathrm{H}$, pointed by black arrows) in scramble tumor, but very week Ki-67 staining in the center of scramble tumor mass (Figure 7l, pointed by black arrows) and CT30 tumor mass (Figure 7 , J-K, pointed by black arrows). The quantitative data demonstrate that Ki-67 staining was significantly elevated in the invading single, cluster, subpial, and perivascular cells in scramble xenograft $(P<0.01)$ as well as the edge of scramble tumor mass $(P<0.05)$ when compared with the center of scramble tumor mass and CT30 tumor mass (Figure $7 \mathrm{~L}$ ). These results suggest that the high level of MMP-9-associated cell motility and proliferation may contribute to extensive infiltration of U1242 MG xenograft tumor.

\section{EGF-Induced MMP-9 Up-Regulation Is Essential for Cell Invasion and Colony Formation in U1242 MG Cells}

Since high MMP-9 expression directly correlated with the invasion in vitro and in vivo in the U1242 MG cells, we 
A

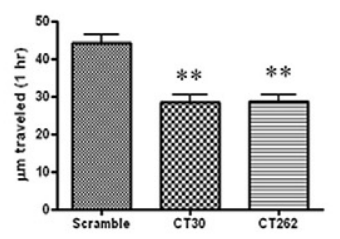

C
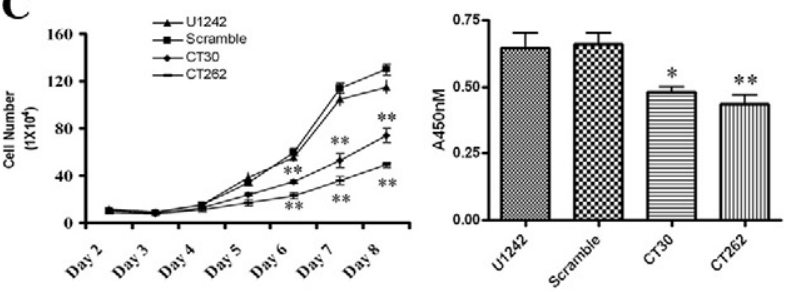

Ki67 Staining in Scramble Xenograft Tumor

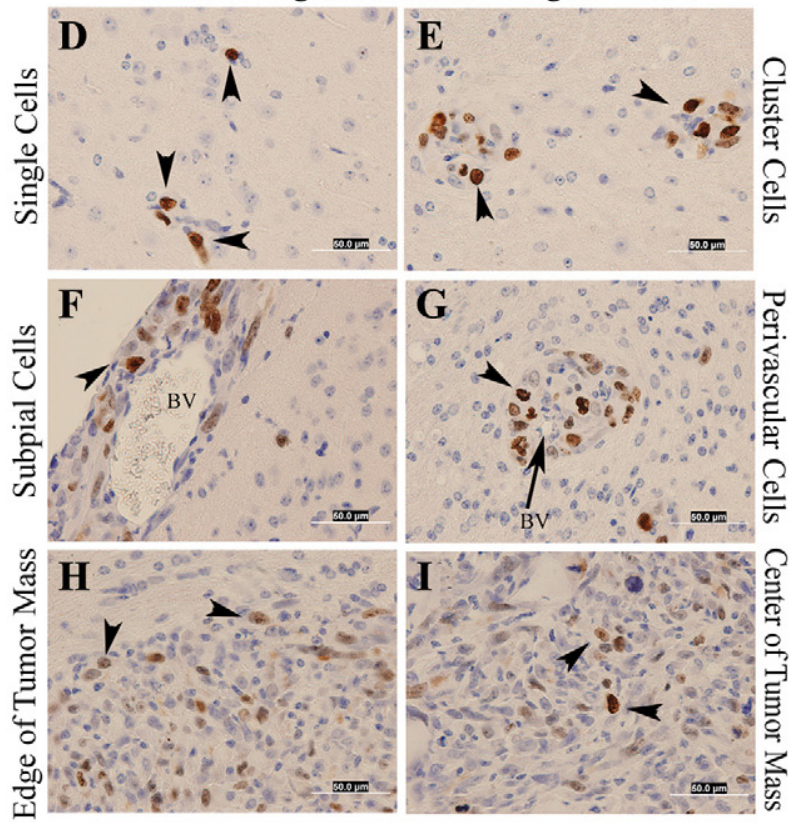

Ki67 Staining in CT30 clone Xenograft Tumor

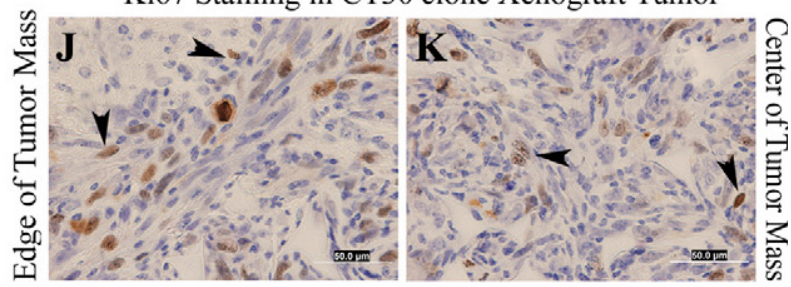

$\mathbf{L}$

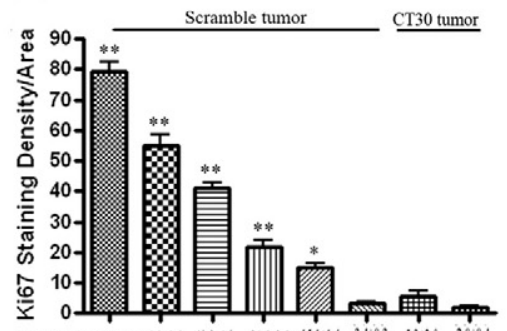

single cells

[0. cluster cells

Derivascular cells

mon subpial cells

wana edge of tumor mass

center of tumor mass

에 edge of tumor mass

center of tumor mass investigated whether increasing MMP-9 expression would alter cell invasion. EGFR activation has been shown to promote MMP-9 activation in other cancer cell types. ${ }^{25-27}$ To study the association between MMP-9 and EGFR in GBM cell invasion and colony formation, we first investigated the correlation between EGFR expression and MMP-9 levels in GBM patient specimens and U1242 MG cells by RT-PCR and Western blot analysis. As shown in Figure 8A, the high MMP-9-expressing GBM patient specimens ( $n=10)$ and U1242 MG cells expressed higher levels of EGFR mRNA transcript and protein, while the nonneoplastic human TL specimens $(n=10)$ exhibited very weak EGFR expression. The $\beta$-actin and tubulin were used as loading controls for RT-PCR and western blotting, respectively.

We then asked whether the activation of EGFR by EGF would alter the MMP-9 expression, gelatinolytic activity, and cell invasion in U1242 MG cells. U1242 MG cells were serum-starved for 24 hours and then treated with EGF (25 ng/ml) for 24 hours, which is the best condition for inducing phosphorylation of ERK1 and ERK2 in U1242 MG cells from our previous study ${ }^{37}$ and stimulating MMP-9 gelatinolytic activity and cell invasion the most in the U1242 MG cells from our preliminary experiments (data not shown). The results showed that the EGF significantly increased MMP-9 mRNA by fivefold (Figure 8B, top panel, $P<0.01$ ), protein expression (Figure 8B, second and fourth panel), gelatinolytic activity (but not MMP-2, Figure 8B, third panel), and cell invasion in vitro by threefold (Figure 8B, bottom panel, $P<0.01$ ) in the U1242 MG cells. However, under the similar experimental conditions, EGF failed to alter the gelatinolytic activity of secreted MMP-9 in EGFR-positive/low MMP-9 expressing U87 MG and U251 MG cells (data not shown). To show if the same patterns of EGF-induced increase in MMP-9 expression also occur in the tumor cells from patients, we obtained primary EGFR-positive/high MMP-9-expressing GBM tumor cell line (\#8HGBM), which isolated from a GBM patient by Mayo Clinic. Following EGF treatment, MMP-9 gelatinolytic activity and cell invasion were significantly increased (Supplemental Figure S1 available at http://ajp.amjpathol.org), indicating that high MMP-9 expression occurs in the EGFR-positive primary GBM cells.

To further identify the role of MMP-9 in EGF-induced U1242 MG cell invasion, MMP-9 shRNA CT30 and shRNA CT262 clones were treated with EGF. Importantly, EGF

Figure 7. Effects of MMP-9 silence on cell motility and proliferation in U1242 MG cells. A: Cell motility of scramble, CT30, and CT262 cells. B: Cell death of U1242 MG, scramble, CT30, and CT262 cells from day 3 to day 8. C: Cell viability of U1242 MG, scramble, CT30, and CT262 cells from day 2 to day 8 (left panel) and cell proliferation on day 8 (right panel). D-I: The sections of scramble xenograft were stained with Ki-67. Nuclear staining (DAB, brown) indicates $\mathrm{Ki}-67$ positive staining. The black arrows indicate Ki-67 positive-staining in single cells $(\mathbf{D})$, cluster cells $(\mathbf{E})$, subpial cells $(\mathbf{F})$, perivascular cells $(\mathbf{G})$, the edge of tumor mass $(\mathbf{H})$, and center of tumor mass in scramble xenograft (I). The pictures are $\times 400$ magnification. BV, blood vessel. J-K: The sections of CT30 xenograft were stained with Ki-67. Nuclear staining (DAB, brown) indicates Ki-67 positive staining. The black arrows indicate Ki-67 positive-staining cells in the edge of tumor mass $(\mathbf{J})$, and the center of tumor mass $(\mathbf{K})$. The pictures are $\times 400$ magnification. L: Densitometric quantitative analysis of Ki-67 staining in the scramble and CT30 xenograft tumors. Data shown are the mean \pm SEM values from four or six different fields for each group. ${ }^{*} P<0.05,{ }^{* *} P<0.01$. 

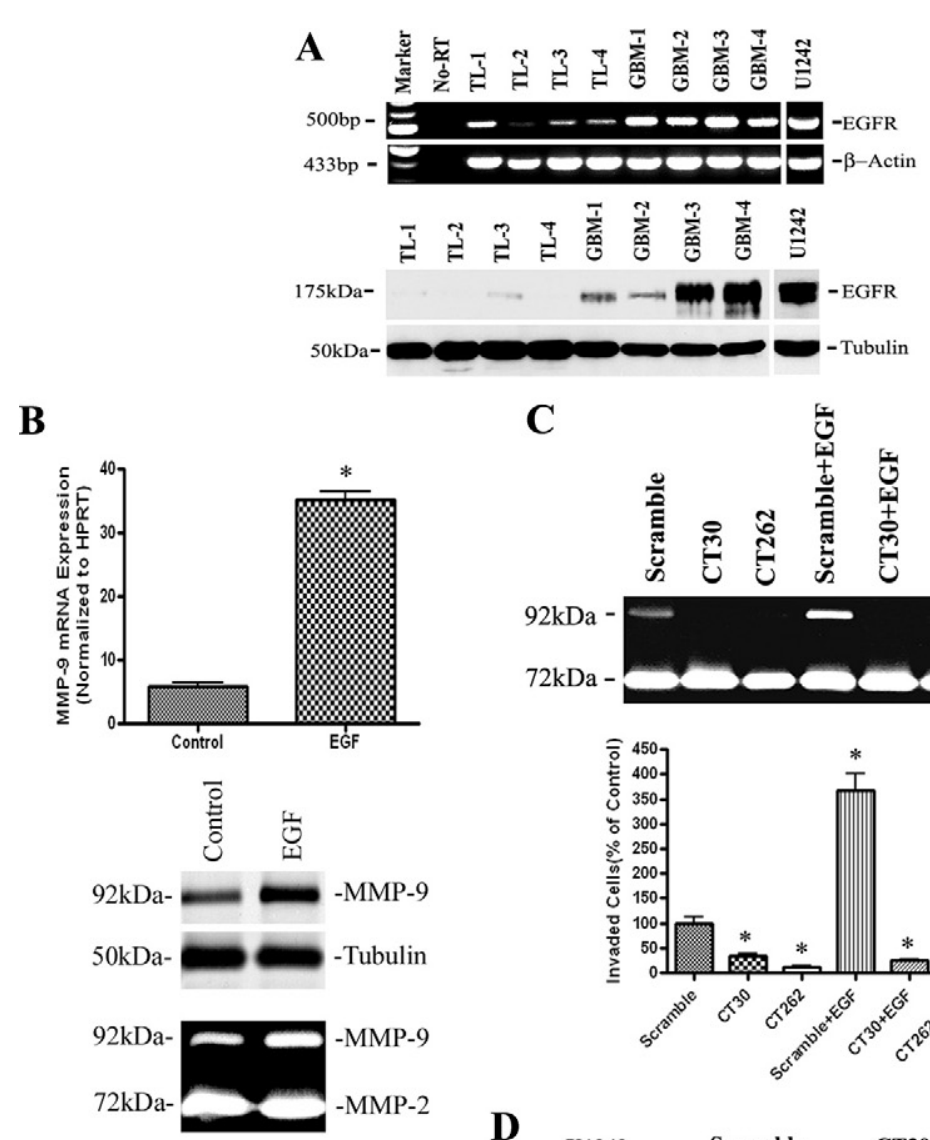

B

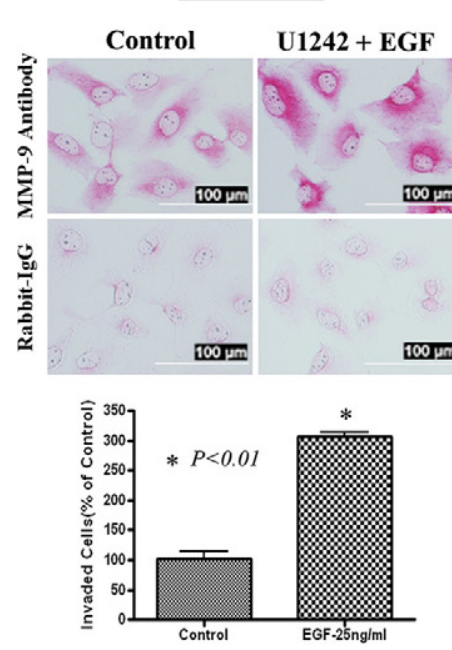

C
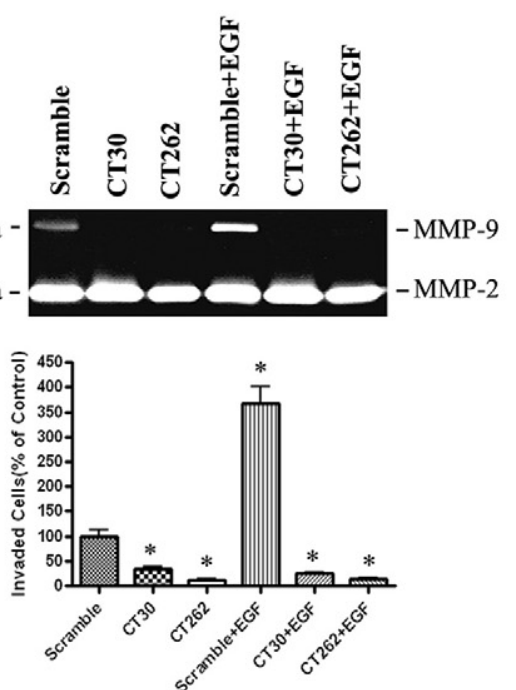

D

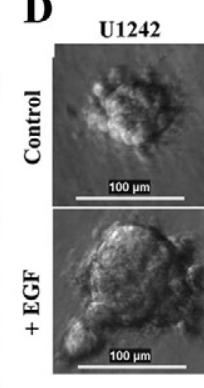

Figure 8. MMP-9 is involved in EGF-stimulated U1242 MG cell invasion and colony formation A: Expression of EGFR mRNA (top panel, RTPCR) and protein (bottom panel, Western blot) in human TLs, GBM patient specimens, and U1242 MG cells. Equal amount of proteins (25 $\mu \mathrm{g} /$ lane) was loaded. B: EGF-stimulated the expression of MMP-9 mRNA, protein and cell invasion in U1242 MG cells. Top panel: Real-time PCR, second panel: Western blot, third panel Zymogram, fourth panel: immunocytochemistry ( $\times 400$ magnification). Red color indicates MMP-9 immunoreactivity. The normal rabbit IgG was used as control for immunohistochemical staining. Bottom panel: EGF-induced U1242 MG cell invasion. HPRT: Hypoxanthine-guanine phosphoribosyltransferase C: Silencing of MMP-9 blocked EGF-induced MMP-9 gelatinolytic activity and cell invasion in U1242 MG cells EGF stimulated MMP-9 gelatinolytic activity in scramble cells but failed to stimulate MMP-9 gelatinolytic activity in MMP-9 deficient clones (top panel). EGF stimulated cell invasion in scramble cells but failed to stimulate cell invasion in MMP-9 deficient clones (bottom panel). The number of invaded cells in scramble was designated as $100 \%$. Data shown are the mean \pm SEM values from three separate experiments for each group. D: Microscopically visualized colony formation in U1242 MG, scramble, and MMP-9 shRNA infected cells (CT30 and CT262) in soft agar after 3 weeks in the presence or absence of $\mathrm{EGF}(25 \mathrm{ng} / \mathrm{ml}$ ) (top panel). The bottom panel is the bar graph of colony area in these cells with or without EGF treatment. The colony area of U1242 MG cells (control) or scramble cells was designated as $100 \%$. Data shown are the mean \pm SEM values from three separate experiments for each group. ${ }^{*} P<0.01$. increased MMP-9 gelatinolytic activity (Figure $8 \mathrm{C}$, top panel) and cell invasion in vitro by 3.3-fold in the scramble control (Figure 8C, bottom panel, $P<0.01$ ), but not MMP-9 gelatinolytic activity and invasive ability in both MMP-9 shRNA clones. To determine whether down-regulation of MMP-9 expression in U1242 MG cells diminishes levels of EGFR in CT30 and CT262 clones, which would prevent the initiation of EGF cascade, we compared the EGFR expression by Western blot among the scramble, CT30 and CT262 clones. The results showed that down-regulation of MMP-9 expression did not change the level of EGFR expression (data not shown).
Since anchorage-independent growth is one of the hallmarks of transformation and is considered the most accurate and stringent in vitro assay for detecting malignant transformation of cells, we used the soft agar colony formation assay to monitor anchorage-independent growth in the U1242 MG cells, scramble cells and MMP9 -silenced clones in the presence or absence of EGF. Our results showed that the CT30 and CT262 clones formed less colony $(29.5 \pm 4.5$ and $12.0 \pm 3.0$, respectively) compared with colony in the scramble cells (217.0 $\pm 11.0, P<0.01)$. In addition, the size of colony in the CT30 and CT262 clones showed $66.9 \%$ and $83.5 \%$ 
reductions when compared with scramble (Figure 8D). The EGF significantly stimulated the colony growth of the U1242 MG cells and scramble cells (about 2.8 fold, $P<$ 0.01 ), but failed to stimulate the colony growth in the MMP-9-deficiency clones (Figure 8D). The results clearly demonstrate that MMP-9 is critical for basal and EGFstimulated cell invasion and colony formation in U1242 MG cells.

\section{EGF Induces MMP-9 Gelatinolytic Activity, Cell Invasion, and Colony Formation Via EGFR/ Ras/MEK and PI3K/AKT Signaling Pathways in U1242 MG Cells}

Although Ras is rarely mutated in gliomas, its activity increases in high grade gliomas. ${ }^{44-46} \mathrm{H}$-Ras pathway activation cooperates with hTERT expression and inactivation of p53/pRb transformed NHA to form intracranial tumors. ${ }^{47}$ Also Ras is one of the downstream targets for EGFR and is an activator of many downstream signaling effectors such as MEK $1 / 2$ and PI3K. ${ }^{48,49}$ Recently, it was reported that inhibiting PI3K may be useful in treating glioma. ${ }^{50}$ Since EGF induces phosphorylation of ERK1 and ERK2 in U1242 MG cells ${ }^{37}$ and the phosphorylation of mitogen-activated protein kinase (MAPK/ERK) increases in glioblastoma specimens compared with nonneoplastic TLs, ${ }^{51}$ we determined whether EGFR/Ras/ MEK and PI3K/AKT signaling pathway plays a role in EGF-induced elevation of MMP-9 gelatinolytic activity, cell invasion and colony formation in U1242 MG cells. The EGFR tyrosine kinase inhibitor AG1478 (1 $\mu \mathrm{mol} / \mathrm{L})$, MEK $1 / 2$ inhibitor U0126 (10 $\mu \mathrm{mol} / \mathrm{L})$, or PI3K inhibitor LY294002 (3 $\mu \mathrm{mol} / \mathrm{L}$ and $10 \mu \mathrm{mol} / \mathrm{L})$ was incubated with U1242 MG cells for 2 hours and then stimulated with EGF (25 ng/ml) for 24 hours. The dominant negative Ras (RasN17) was also used to attenuate Ras activity. ${ }^{52}$ U1242 MG cells were transfected with vector encoding dominant negative RasN17 and control vector (as shown in Figure 9C, top panel) and then treated with EGF (25 $\mathrm{ng} / \mathrm{ml}$ ) for 24 hours. The results showed that AG1478, dominant negative RasN17 expression, and U0126 significantly blocked EGF-induced MMP-9 secretion (Figure 9, $A$ and $C$ ), cell invasion (Figure $9, A$ and $C$ ), and colony formation (Figure 9, B and D) in U1242 MG cells, respectively. Furthermore, AG1478, dominant negative RasN17 and U0126 also significantly reduced basal MMP-9 gelatinolytic activity (but not MMP-2 activity), cell invasion and colony formation (Figure 9, A-D). LY294002 (3 $\mu \mathrm{mol} / \mathrm{L}$ and $10 \mu \mathrm{mol} / \mathrm{L}$ ) completely blocked basal Akt (Ser473) phosphorylation, but only $10 \mu \mathrm{mol} / \mathrm{L}$ completely blocked EGF-induced Akt phosphorylation in U1242 MG cells (Supplemental Figure S2 available at $h$ ttp://ajp. amjpathol.org). Also LY294002 (10 $\mu \mathrm{mol} / \mathrm{L})$ significantly blocked EGF-induced MMP-9 mRNA (Supplemental Figure S3 available at $h$ ttp://ajp.amjpathol.org), MMP-9 gelatinolytic activity (Figure 9A), cell invasion (Figure 9A), and colony formation (Figure 9B) in U1242 MG cells, respectively. In addition, LY294002 (10 $\mu \mathrm{mol} / \mathrm{L})$ also significantly blocked basal MMP-9 gelatinolytic activity (Figure 9A), cell invasion (Figure 9A), and colony formation (Figure 9B) in U1242 MG cells, respectively. These results demonstrate that EGFR/Ras/MEK and PI3K/AKT signaling pathways contribute to basal and EGF-stimulated MMP-9 gelatinolytic activity, invasion, and colony formation in U1242 MG cells (Figure 9E).

\section{Discussion}

In the present study, we have established and characterized an extensive and infiltrative intracranial human U1242 MG xenograft model. It was observed that U1242 MG xenograft tumor cells invaded around blood vessels (perivascular infiltration), infiltrated extensively into the brain parenchyma, even into subpial regions (subpial infiltration) as single and cluster cells; with microvascular proliferation as tortuous vasculature within the infiltrating tumor bed as well as geographic necrosis in the tumor mass. The key characteristic features of human GBM are their extensive infiltration into surrounding normal tissues by single cell spread, presence of microvascular proliferation with classic angiogenesis or/and with glomeruloid structures, ${ }^{53,54}$ and multiple area of necrosis with or without palisading. ${ }^{55}$ Perivascular and subpial cellular infiltration of GBM tumor cells by individual or perivascular spread have been referred to as the "secondary structures of Scherer" that is typically seen in infiltrating gliomas. ${ }^{41,42}$ Therefore, our U1242 MG xenograft model closely resembles the key features of human GBM such as the perivascular and subpial cellular infiltration, microvascular proliferation with classic angiogenesis and geographic necrosis. In this study, the U251 MG and U87 MG xenograft models only exhibited peritumoral infiltration and tumor mass formation, which is much less aggressive than U1242 MG xenograft tumor and different from human GBM, but consistent with other reports. ${ }^{16}$ It has been shown that the U87 MG human xenograft model is the most profusely vascularized tumor among the rodent xenograft models ${ }^{16}$ and proved useful for assessing GBM angiogenesis and antiangiogenic therapeutic approaches. ${ }^{11-13}$ However, the U1242 MG xenograft model displayed much higher density of microvessels compared with U87 the MG xenograft. Although tumor cells show diffuse brain invasion as single cells in syngeneic experimental models, such as GL26 mouse glioma cells in C57BL6 mice and CNS1 or C6 rat glioma cells in rats, the anatomical invasion pattern is not as extensive as those of spontaneous GBM in human, and also syngeneic models cannot be used for study of human-targeted therapies. ${ }^{14-16}$ In addition, the C6 glioma cell line is a chemically induced rat glioma cell line, which has different responsive patterns to growth factors and expression profiles of growth factors and proteases compared with the human GBM cell lines (data not shown). Recently, GBM stem-like cells (GBM-SC) have been isolated and cultured from human GBM tumor tissues. ${ }^{56-58}$ The GBMSC-derived tumors displayed a variety of characteristics on intracerebral implantation in mice. Some GBM-SCderived tumors showed a highly invasive nature but without the formation of necrosis, as opposed to subcutane- 


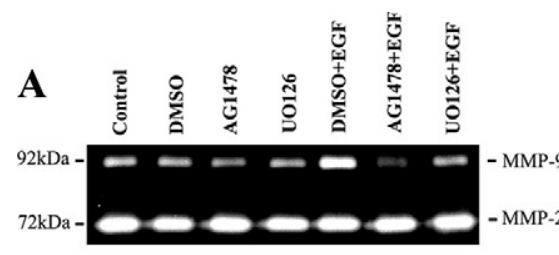

\section{B}

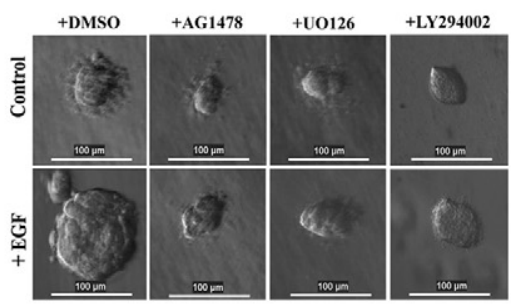

Figure 9. EGF-stimulated MMP-9 gelatinolytic activity, cell invasion, and colony formation in U1242 MG cells are EGFR/Ras/MEK and PI3K/ AKT signaling pathway dependents. A: EGFR tyrosine kinas inhibitor AG1478 (1 $\mu \mathrm{mol} / \mathrm{L})$, MEK1/2 inhibitor UO $126(10 \mu \mathrm{mol} / \mathrm{L})$, and PI3K

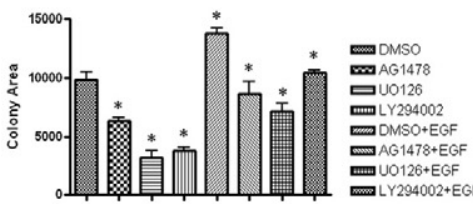
inhibitor LY294002 (10 $\mu \mathrm{mol} / \mathrm{L})$ reduced basal and EGF-induced MMP-9 gelatinolytic activity (top and middle panels) and cell invasion (bottom panel) in U1242 MG cells. The number of invaded cell in U1242 MG cells represents three separate experiments for each group and data shown are the mean \pm SEM values. MMP-2 gelatinolytic activity was not affected by EGF ( 25 $\mathrm{ng} / \mathrm{ml}$ ) and inhibitors. B: Microscopically visualized colony formation of U1242 MG cells in soft agar after three weeks in the presence or absence of EGF $(25 \mathrm{ng} / \mathrm{ml})$, AG1478 (1 $\mu \mathrm{mol} / \mathrm{L})$, $\mathrm{UO} 126(10 \mu \mathrm{mol} / \mathrm{L})$ (top panel), and LY294002 $(10 \mu \mathrm{mol} / \mathrm{L})$. Bottom panel is the bar graph of colony area in U1242 MG cells with treatments. The colony area of U1242 MG cells represents three separate experiments for each group and data shown are the mean \pm SEM values. C: Overexpression of dominant negative Ras (RasN17, top panel) reduced basal and EGF-induced MMP-9 gelatinolytic activity (middle panel), and cell invasion (bottom panel). The number of invaded cells in Neo-Vector was designated as $100 \%$. Data shown are the mean \pm SEM values from three separate experiments for each group. D: Microscopically visualized colony formation of Neo-vector and RasN17-C12 cells in soft agar in presence or absence of EGF $(25 \mathrm{ng} / \mathrm{ml}$ ) (top panel). The bottom panel is the bar graph of colony area in Neo-vector and RasN17-C12 cells with EGF treatment. The colony area of Neovector cell was designated as $100 \%$. Data shown are the mean \pm SEM values from three separate experiments for each group. E: Mechanistic scheme for EGF-stimulated MMP-9 gelatinolytic activity, cell invasion, and colony formation. ${ }^{*} P$ $<0.01$.

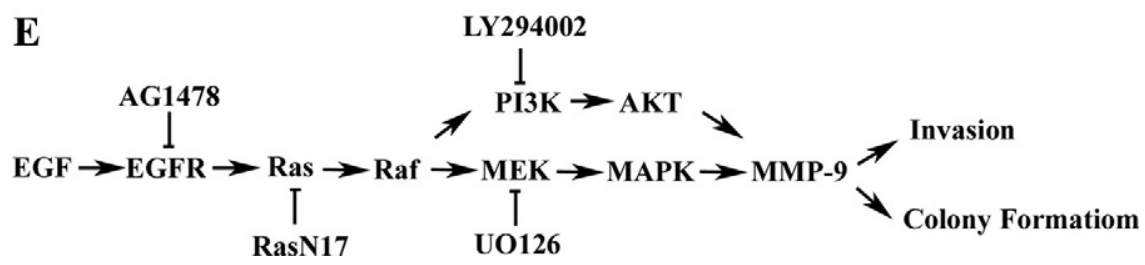

ous injection. ${ }^{57}$ Others possessed necrosis but only formed well-delineated tumor masses. ${ }^{58}$ Notably, no any individual GBM-SC-derived tumor simultaneously resembles the extensive infiltration, hypervascular, and necrotic behavior of GBM so far. Conversely, our U1242 MG xenograft model exhibits key features of extensive invasion, hypervascularity and clear areas of necrosis, which is closer to patient GBM than any other previously available human GBM cell lines $^{16}$ or GBM stem-like cells xenograft models, ${ }^{56-58}$ as well as syngeneic models. ${ }^{14-16}$

Previous studies ${ }^{19,59-61}$ showed that the levels of MMP-9 mRNA, protein, and activity were significantly higher in human malignant astrocytomas, especially in
GBM, and strong MMP-9 cytoplasmic immunoreactivity was detected in the tumor cells. We also confirmed that GBM patient specimens expressed high levels of MMP-9 mRNA, protein, and gelatinolytic activity, but low levels of MMP-2. MMP-9 was present in human GBM tumor mass as well as in tumor cells diffusely invading adjacent brain tissue. These results indicate that MMP-9, not MMP-2, may play a critical role in GBM cell invasion in vivo.

We explored how MMP-9 plays a role in GBM extensive invasive behavior. We demonstrated that only highly invasive-tumor-formed U1242 MG cell line expressed high level of pro- or activated-MMP-9 and showed high cell invasive ability in vitro. In addition, U1242 MG xenograft tumor cells, eg, single, clusters, perivascular, and 
subpial tumor cells significantly expressed high positive MMP-9 signals compared with tumor mass. However, nonextensive invasive tumor-formed U87 MG and U251 MG cell lines expressed low level of MMP-9. U87 MG and U251 MG xenograft tumor cells also exhibited low level of MMP-9 in tumor mass. MMP-2 and UPA expression/activity was similar among U1242 MG, U87 MG, and U251 MG cell lines. More significantly, MMP-9 silenced clones, especially the CT262 clone, showed significantly reduced cell invasive ability and colony formation in soft agar in vitro. Intracranial implantation of CT262 clone almost failed to form tumor mass and the CT30 clone formed smaller tumor mass that failed to invade around blood vessel or in subpial regions as single or clusters cells spread in NOD SCID mouse brain. The CT30 cloneformed tumor mass expressed very weak MMP-9. In contrast, the scramble clone-formed tumor, like wild-type U1242 MG cells or human GBM, invaded extensively into the normal brain as single cell, clusters, perivascular, and subpial cellular infiltrative pattern. These infiltrating tumor cells also expressed robust MMP-9. Moreover, MMP-9 functional-blocking antibody and MMP-9 inhibitor significantly blocked U1242 MG cell invasion in vitro, suggesting MMP-9 is functionally active. Our previous study demonstrated that U1242 MG cells highly expressed both UPA and MMP-9, as well as UPA-mediated $92 \mathrm{kDa}$ proenzyme MMP-9 activation promotes U1242 MG cell invasion in vitro. ${ }^{22}$ The functional rescue experiments by an addition of exogenous pro-MMP-9 enzyme to MMP-9silenced by $92 \%$ clone CT30 and by $96 \%$ clone CT262 significantly increased their invasive ability by 0.40 and 2.93 folds, respectively. These results may indicate that functionally active or uPA-activated MMP-9 proteolytic was involved in increased U1242 MG cell invasion in vitro. There are a number of reports wherein MMP-9 alone or combinations with one or two genes including UPA, urokinase receptor, or cathepsin B was targeted by antisense/ siRNA shows significantly inhibition of SNB 19 glioma invasion in vitro and tumor growth in vivo. ${ }^{24,62-64} \mathrm{How}$ ever, the SNB19 glioma cells-formed tumors display wellcircumscribed tumor mass without extensive infiltration, which is similar to our low MMP-9 expressing U87 MG or U251 MG cells-formed tumor. We therefore obtained SNB19 cells from Dr. Alfred Yung and compared the MMP-9/MMP-2 activities in these cells with our infiltrative U-1242 MG cells. The data showed that SNB19 cells expressed very low levels of MMP-9 activity in control or EGF-treatment, and the MMP-2 activity was also lower in SNB19 cells compared with U1242 MG cells, but is similar to U87 MG and U251MG cells (data not shown). These results proved that high level of MMP-9 expression is essential for U1242 MG tumor cells highly extensive single, clusters, perivascular, and subpial infiltration in the brain. All data clearly favor the role of high level of MMP-9 in extensive infiltration of GBM in vivo.

It was reported that MMP-9 siRNA inhibit human gliomas cell proliferation. ${ }^{65}$ Our results also showed that silencing of MMP-9 with shRNA decreased cell motility, the number of viable cells and cell proliferation, but did not result in cell death. Analysis of Ki-67 immunohistochemistry revealed that high MMP-9 expressing-related extensive infiltrating tumor cells exhibited significantly high proliferative ability, whereas low MMP-9 expressing nonextensive infiltrating tumor mass cells in MMP-9 silenced clone CT30 displayed low proliferative ability. Therefore, the results suggest that high expressing MMP-9 facilitate extensive infiltration by increasing cell motility and proliferation.

Our PECAM-1 staining data demonstrated that the high MMP-9 expressing-mediated high proliferative, extensive infiltrating tumors in U1242 MG or scramble xenografts induced hypervascularity with large, tortuous vasculature and significant high vessel density, whereas low MMP-9 expressing noninvasive U87 MG and CT30 xenograft displayed lower vessel density. These results indicate that high expressing MMP-9 in infiltrating tumor cells may play a role on vascular proliferation, which is consistent with reports that down-regulation of MMP-9 inhibited capillary-like network formation in endothelial cells. ${ }^{63-65}$

Active MMP-9 expression has been correlated with 73\% of EGFR-overexpressing GBM tumor. ${ }^{60}$ Our results displayed that MMP-9 overexpressing GBM patient specimens and U1242 MG cells also expressed EGFR, indicating that MMP-9 expression in the human GBM maybe tightly regulated by EGF/EGFR amplification/overexpression. In this study, EGF greatly stimulated MMP-9 expression at mRNA and protein level, cell invasion, and soft agar colony formation in U1242 MG cells, but failed to stimulate MMP-9 expression, cell invasion, and colony formation in shRNA-silenced MMP-9 clones, indicating that EGF-stimulated MMP-9 is responsible for promoting cell invasion and colony formation. In our functional studies, a specific EGFR tyrosine kinase inhibitor (AG1478) completely abolished EGF-induced EGFR phosphorylation (data not shown), MMP-9 activity, cell invasion, and colony formation in U1242 MG cells. AG1478 also inhibited basal MMP-9 activity, cell invasion, and colony growth in U1242 MG cells. Overall the results further suggest that both endogenous and exogenous EGF-induced EGFR activation increase MMP-9 expression, cell invasion, and anchorage-independent growth in U1242 MG cells.

EGF-induced cellular processes are mediated through a number of signaling cascades, including the Ras/Raf/ MEK/MAPK and Ras/Raf/PI3K/AKT pathways. Ras proteins are molecular switches with the ability to interact with and activate effector proteins such as PI3K, and MEK1/2. ${ }^{48,49}$ We demonstrated that inhibiting MEK1/2, AKT, and Ras activity by UO126 (10 $\mu \mathrm{mol} / \mathrm{L})$, LY294002 (10 $\mu \mathrm{mol} / \mathrm{L}$ ), and dominant negative RasN17, respectively, were sufficient to significantly abolish EGF-induced MMP-9 gelatinolytic activity, cell invasion, and colony formation in U1242 MG cells. These results proved that EGF stimulates MMP-9 gelatinolytic activity, cell invasion, and colony formation in U1242 MG cells through Ras/ MEK- and PI3K/AKT-dependent signaling pathways. These results agreed with the previous published data in other types of cancer cells. ${ }^{25,27}$

Recently, Li et al reported ${ }^{66}$ that inhibition of PTEN in wt-PTEN/mu-p53 U1242 MG cells that harbor a gain-offunction mutation of p53 leads to down-regulation of mu- 
p53 protein, inhibition of cell proliferation and in vivo xenograft growth, while PTEN restoration leads opposite effects in mu-p53/PTEN-null SNB19 cells, as well as to an increase in wt-p53 protein levels, but inhibition of cell proliferation and cell survival in wt-p53/mu-PTEN U87 cells, indicating the tumor-promoting properties of PTEN are mu-p53-dependent. Mu-p53 was associated strongly with MMP-9 overexpression in the head and neck squamous cell carcinoma tumors. ${ }^{67}$ Stable insertion of a dominant-negative mutant p53 in human wt-p53 breast carcinoma increase EGFR phosphorylation and MMP-9 expression. ${ }^{68}$ However, reintroduction of wt-p53 into mup53 human soft tissue sarcoma cell lines inhibited MMP-9 expression and tumor cell invasiveness. ${ }^{69}$ Our data demonstrated that wt-PTEN/mu-p53 U1242 MG xenograft model expressed high level of MMP-9 and EGFR, as well as exhibited MMP-9-induced highly infiltrative feature and microvascular proliferation, while mu-PTEN/mu-p53 U251 MG and mu-PTEN/wt-p53 U87 MG cells xenograft models expressed low level of MMP-9 and displayed non-invasive feature. These results suggest that the mup53-dependent tumor-promoting properties of wt-PTEN in U1242 MG cells may promote tumor invasion and microvascular proliferation in vivo via increasing MMP-9 expression, while mu-PTEN in U251 MG and U87 MG cells may inhibit tumor infiltration via decreasing MMP-9 expression. Although the low frequency of simultaneous wt-PTEN and mu-p53 $3^{70}(20 \%)$ or mu-PTEN and mu-p53 $3^{71}$ $(33 \%)$ or wt-p53 and mu-PTEN ${ }^{70}(20 \%)$ are found in human GBM patient specimens, the genetic defects of GBMs may truly reflect the considerable heterogeneous of GBM in nature.

In summary, our study provides compelling evidence that high level of MMP-9 facilitates the extensive single, clusters, perivascular, and subpial infiltrative invasion in U1242 MG xenograft tumor by degrading the ECM, inducing cell motility, cell proliferation, and vascular proliferation. Our U1242 MG mouse model could be a valuable experimental and preclinical model for studying GBM extensive invasion, assessing GBM angiogenesis, and testing novel therapeutic agents for the management of GBM, and MMP-9 may be a putative target for small molecule, as well as gene therapy to reduce the extensive infiltration of glioblastomas and thus, making these tumors a local disease.

\section{Acknowledgment}

We gratefully acknowledge Dr. Duo Li (Department of Biochemistry and Molecular Genetics, University of Virginia) for providing us with RasN17 constructs.

\section{References}

1. Lun X, Yang W, Alain T, Shi ZQ, Muzik H, Barrett JW, McFadden G, Bell J, Hamilton MG, Senger DL, Forsyth PA: Myxoma virus is a novel oncolytic virus with significant antitumor activity against experimental human gliomas. Cancer Res 2005, 65:9982-9990

2. Luwor RB, Johns TG, Murone C, Huang HJ, Cavenee WK, Ritter G, Old LJ, Burgess AW, Scott AM: Monoclonal antibody 806 inhibits the growth of tumor xenografts expressing either the de2-7 or amplified epidermal growth factor receptor (EGFR) but not wild-type EGFR. Cancer Res 2001, 61:5355-5361

3. Tentori L, Leonetti C, Scarsella M, D'Amati G, Vergati M, Portarena I, Xu W, Kalish V, Zupi G, Zhang J, Graziani G: Systemic administration of GPI 15427, a novel poly(ADP-ribose) polymerase-1 inhibitor, increases the antitumor activity of temozolomide against intracranial melanoma, glioma, lymphoma. Clin Cancer Res 2003, 9:5370-5379

4. Kawakami K, Kawakami M, Kioi M, Husain SR, Puri RK: Distribution kinetics of targeted cytotoxin in glioma by bolus or convection-enhanced delivery in a murine model. J Neurosurg 2004, 101:10041011

5. Cirielli C, Inyaku K, Capogrossi MC, Yuan X, Williams JA: Adenovirusmediated wild-type p53 expression induces apoptosis and suppresses tumorigenesis of experimental intracranial human malignant glioma. J Neurooncol 1999, 43:99-108

6. Fukushima T, Tezuka T, Shimomura T, Nakano S, Kataoka H: Silencing of insulin-like growth factor-binding protein-2 in human glioblastoma cells reduces both invasiveness and expression of progressionassociated gene CD24. J Biol Chem 2007, 282:18634-18644

7. Uchinokura S, Miyata S, Fukushima T, Itoh H, Nakano S, Wakisaka S, Kataoka H: Role of hepatocyte growth factor activator (HGF activator) in invasive growth of human glioblastoma cells in vivo. Int $\mathrm{J}$ Cancer 2006, 118:583-592

8. Conrad C, Miller CR, Ji Y, Gomez-Manzano C, Bharara S, McMurray JS, Lang FF, Wong F, Sawaya R, Yung WK, Fueyo J: Delta24-hyCD adenovirus suppresses glioma growth in vivo by combining oncolysis and chemosensitization. Cancer Gene Ther 2005, 12:284-294

9. Jiang H, Gomez-Manzano C, Alemany R, Medrano D, Alonso M, Bekele BN, Lin E, Conrad CC, Yung WK, Fueyo J: Comparative effect of oncolytic adenoviruses with $\mathrm{E} 1 \mathrm{~A}-55 \mathrm{kDa}$ or $\mathrm{E} 1 \mathrm{~B}-55 \mathrm{kDa}$ deletions in malignant gliomas. Neoplasia 2005, 7:48-56

10. Samoto K, Ehtesham M, Perng GC, Hashizume K, Wechsler SL, Nesburn AB, Black KL, Yu JS: A herpes simplex virus type 1 mutant with gamma 34.5 and LAT deletions effectively oncolyses human U87 glioblastomas in nude mice. Neurosurgery 2002, 50:599-605

11. Kirsch M, Strasser J, Allende R, Bello L, Zhang J, Black PM: Angiostatin suppresses malignant glioma growth in vivo. Cancer Res 1998, 58:4654-4659

12. Lund EL, Bastholm L, Kristjansen PE: Therapeutic synergy of TNP470 and ionizing radiation: effects on tumor growth, vessel morphology, and angiogenesis in human glioblastoma multiforme xenografts. Clin Cancer Res 2000, 6:971-978

13. Schmidt NO, Ziu M, Carrabba G, Giussani C, Bello L, Sun Y, Schmidt K, Albert M, Black PM, Carroll RS: Antiangiogenic therapy by local intracerebral microinfusion improves treatment efficiency and survival in an orthotopic human glioblastoma model. Clin Cancer Res 2004, 10:1255-1262

14. Bernstein JJ, Goldberg WJ, Laws ER Jr, Conger D, Morreale V, Wood LR: C6 glioma cell invasion and migration of rat brain after neural homografting: ultrastructure. Neurosurgery 1990, 26:622-628

15. Chicoine MR, Silbergeld DL: Invading C6 glioma cells maintaining tumorigenicity. J Neurosurg 1995, 83:665-671

16. Candolfi M, Curtin JF, Nichols WS, Muhammad AG, King GD, Pluhar GE, McNiel EA, Ohlfest JR, Freese AB, Moore PF, Lerner J, Lowenstein PR, Castro MG: Intracranial glioblastoma models in preclinical neurooncology: neuropathological characterization and tumor progression. J Neurooncol 2007, 85:133-148

17. Duffy MJ, Duggan C: The urokinase plasminogen activator system: a rich source of tumour markers for the individualised management of patients with cancer. Clin Biochem 2004, 37:541-548

18. Egeblad M, Werb Z: New functions for the matrix metalloproteinases in cancer progression. Nat Rev Cancer 2002, 2:161-174

19. Rao JS, Yamamoto M, Mohaman S, Gokaslan ZL, Stetler-Stevenson WG, Rao VH, Fuller GN, Liotta LA, Nicholson GL, Sawaya RE: Expression and localization of $92 \mathrm{kDa}$ type IV collagenase/gelatinase B (MMP-9) in human gliomas. Clin Exp Metastasis 1996, 14:12-18

20. Hsu DW, Efird JT, Hedley-Whyte ET: Prognostic role of urokinase-type plasminogen activator in human gliomas. Am J Pathol 1995, 147:114-123

21. Raithatha SA, Muzik H, Rewcastle NB, Johnston RN, Edwards DR, Forsyth PA: Localization of gelatinase-A and gelatinase-B mRNA and protein in human gliomas. Neuro-Oncol 2000, 2:145-150

22. Zhao Y, Lyons CE Jr, Xiao A, Templeton DJ, Sang QA, Brew K, 
Hussaini IM: Urokinase directly activates matrix metalloproteinases-9: a potential in glioblastoma invasion. Biochem Biophys Res Commun 2008, 369:1215-1220

23. Sawaya R, Go Y, Kyritisis AP, Uhm J, Venkaiah B, Mohanam S, Gokaslan ZL, Rao JS: Elevated levels of Mr 92,000 type IV collagenase during tumor growth in vivo. Biochem Biophys Res Commun 1998, 251:632-636

24. Kondraganti S, Mohanam S, Chintala SK, Kin Y, Jasti SL, Nirmala C, Lakka SS, Adachi Y, Kyritsis AP, Ali-Osman F, Sawaya R, Fuller GN, Rao JS: Selective suppression of matrix metalloproteinase-9 in human glioblastoma cells by antisense gene transfer impairs glioblastoma cell invasion. Cancer Res 2000, 60:6851-6855

25. Kim S, Choi JH, Lim HI, Lee SK, Kim WW, Cho S, Kim JS, Kim JH, Choe JH, Nam SJ, Lee JE, Yang JH: EGF-induced MMP-9 expression is mediated by the JAK3/ERK pathway, but not by the JAK3/STAT-3 pathway in a SKBR3 breast cancer cell line. Cell Signal 2009, 21:892-898

26. O-Charoenrat P, Modjtahedi H, Rhys-Evans P, Court WJ, Box GM, Eccles SA: Epidermal growth factor-like ligands differentially up-regulate matrix metalloproteinase- 9 in head and neck squamous carcinoma cells. Cancer Res 2000, 60:1121-1128

27. Ellerbroek SM, Halbleib JM, Benavidez M, Warmka JK, Wattenberg EV, Stack MS, Hudson LG: Phosphatidylinositol 3-kinase activity in epidermal growth factor-stimulated matrix metalloproteinase-9 production and cell surface association. Cancer Res 2001, 61:18551861

28. Samuels V, Barrett JM, Bockman S, Pantazis CG, Allen MB Jr: Immunocytochemical study of transforming growth factor expression in benign and malignant gliomas. Am J Pathol 1989, 134:894-902

29. Shinojima N, Tada K, Shiraishi S, Kamiryo T, Kochi M, Nakamura H, Makino K, Saya H, Hirano H, Kuratsu J, Oka K, Ishimaru Y, Ushio Y: Prognostic value of epidermal growth factor receptor in patients with glioblastoma multiforme. Cancer Res 2003, 63:6962-6970

30. Liu TF, Tatter SB, Willingham MC, Yang M, Hu JJ, Frankel AE: Growth factor receptor expression varies among high-grade gliomas and normal brain: epidermal growth factor receptor has excellent properties for interstitial fusion protein therapy. Mol Cancer Ther 2003, 2:783-787

31. Khazaie K, Schirrmacher V, Lichtner RB: EGF receptor in neoplasia and metastasis. Cancer Metastasis Rev 1993, 12:255-274

32. Friedman HS, Bigner DD: Glioblastoma multiforme and the epidermal growth factor receptor. N Engl J Med 2005, 353:1997-1999

33. Kang CS, Pu PY, Wang GX, Li YH, Dong L, Wang H: Inhibitory effects of siRNA targeting epidermal growth factor receptor on proliferation and invasion of human glioblastoma cells. Zhonghua Yi Xue Za Zhi 2004, 84:1503-1508

34. Westermark B, Pontén J, Hugosson R: Determinants for the establishment of permanent tissue culture lines from human gliomas. Acta Pathol Microbiol Scand A 1973, 81:791-805

35. Abdel-Fattah R, Xiao A, Bomgardner D, Pease CS, Lopes MB, Hussaini IM: Differential expression of HOX genes in neoplastic and non-neoplastic human astrocytes. J Pathol 2006, 209:15-24

36. Zhao YG, Xiao AZ, Newcomer RG, Park HI, Kang T, Chung LWK Swanson MG, Zhau HE, Kurhanewicz J, Sang QA: Activation of pro-gelatinase $\mathrm{B}$ by endometase/matrilysin-2 promotes invasion of human prostate cancer cells. J Biol Chem 2003, 278:15056-15064

37. Hussaini IM, Brown MD, Karns LR, Carpenter J, Redpath GT, Gonias SL, Vandenberg SR: Epidermal growth factor differentially regulates low density lipoprotein receptor-related protein gene expression in neoplastic and fetal human astrocytes. Glia 1999, 25:71-84

38. Zhao YG, Xiao AZ, Park HI, Newcomer RG, Yan M, Man YG, Heffelfinger SC, Sang QA: Endometase/matrilysin-2 in human breast ductal carcinoma in situ and its inhibition by tissue inhibitors of metalloproteinases-2 and -4 : a putative role in the initiation of breast cancer invasion. Cancer Res 2004, 64:590-598

39. Zhao Y, Xiao A, Dipierro CG, Abdel-Fattah R, Amos S, Redpath GT, Carpenter JE, Pieper RO, Hussaini IM: H-Ras increases urokinase expression and cell invasion in genetically modified human astrocytes through Ras/Raf/MEK signaling pathway. Glia 2008, 56:917924

40. Amos S, Mut M, diPierro CG, Carpenter JE, Xiao A, Kohutek ZA, Redpath GT, Zhao Y, Wang J, Shaffrey ME, Hussaini IM: Protein kinase $\mathrm{C}$-alpha-mediated regulation of low-density lipoprotein recep- tor related protein and urokinase increases astrocytoma invasion. Cancer Res 2007, 67:10241-10251

41. Scherer HJ: Structural development in gliomas. Am J Cancer 1938 , 34:333-351

42. Zagzag D, Esencay M, Mendez O, Yee H, Smirnova I, Huang Y Chiriboga L, Lukyanov E, Liu M, Newcomb EW: Hypoxia- and vascular endothelial growth factor-induced stromal cell-derived factor-1alpha/CXCR4 expression in glioblastomas: one plausible explanation of Scherer's structures. Am J Pathol 2008, 173:545-560

43. Aroca F, Renaud W, Bartoli C, Bouvier-Labit C, Figarella-Branger D: Expression of PECAM-1/CD31 isoforms in human brain gliomas. J Neurooncol 1999, 43:19-25

44. Carpentier AF: New therapeutic approaches in glioblastomas. Bull Cancer 2005, 92:355-359

45. Lassman AB: Molecular biology of gliomas. Curr Neurol Neurosci Rep 2004, 4:228-233

46. Kondo $\mathrm{Y}$, Hollingsworth EF, Kondo S: Molecular targeting for malignant gliomas (Review). Int J Oncol 2004, 24:1101-1109

47. Sonoda Y, Ozawa T, Hirose Y, Aldape KD, McMahon M, Berger MS, Pieper RO: Formation of intracranial tumors by genetically modified human astrocytes defines four pathways critical in the development of human anaplastic astrocytoma. Cancer Res 2001, 61:4956-4960

48. Marshall MS: Ras target proteins in eukaryotic cells. FASEB J 1995, 9:1311-1318

49. Rodriguez-Viciana P, Warne PH, Dhand R, Vanhaesebroeck B, Gout I, Fry MJ, Waterfield MD, Downward J: Phosphatidylinositol-3-OH kinase as a direct target of Ras. Nature 1994, 370:527-532

50. Powis G, Inle NT, Yung WK: Inhibiting PI-3-K for glioma therapy. Cell Cycle 2009, 8:335-347

51. Mandell JW, Hussaini IM, Zecevic M, Weber MJ, VandenBerg SR: Immunohistochemical localization of activated MAP kinase in reactive and neoplastic astrocytes. Am J Pathol 1998, 153:1411-1423

52. Stewart S, Guan KL: The dominant negative Ras mutant N17Ras can inhibit signaling independently of blocking Ras activation. J Biol Chem 2000, 275:8854-8862

53. Wesseling P, Vander Laak JA, Link M, Teepen HL, Ruiter DJ: Quantitative analysis of microvascular changes in diffuse astrocytic neoplasms with increasing grade of malignancy. Hum Pathol 1998, 29:352-358

54. Wesseling P, Ruiter DJ, Burger PC: Angiogenesis in brain tumors pathobiological and clinical aspects. J Neuro-Oncology 1997 32:253-265

55. Liau LM, Becker DP, Cloughesy TF, Bigner DD: Brain tumor immunotherapy. Human Press, 2001, pp. 11

56. Singh SK, Hawkins C, Clarke ID, Squire JA, Bayani J, Hide T, Henkelman RM, Cusimano MD, Dirks PB: Identification of human brain tumour initiating cells. Nature 2004, 432:396-401

57. Galli R, Binda E, Orfanelli U, Cipelletti B, Gritti A, De Vitis S, Fiocco R, Foroni C, Dimeco F, Vescovi A: Isolation and characterization of tumorigenic, stem-like neural precursors from human glioblastoma. Cancer Res 2004, 64:7011-7021

58. Wakimoto H, Kesari S, Farrell CJ, Curry WT Jr, Zaupa C, Aghi M, Kuroda T, Stemmer-Rachamimov A, Shah K, Liu TC, Jeyaretna DS, Debasitis J, Pruszak J, Martuza RL, Rabkin SD: Human glioblastomaderived cancer stem cells: establishment of invasive glioma models and treatment with oncolytic herpes simplex virus vectors. Cancer Res 2009, 69:3472-3481

59. Nakagawa T, Kubota T, Kabuto M, Sato K, Kawano H, Hayakawa $T$, Okada Y: Production of matrix metalloproteinases and tissue inhibitor of metalloproteinases-1 by human brain tumors. J Neurosurg 1994 81:69-77

60. Choe G, Park JK, Jouben-Steele L, Kremen TJ, Liau LM, Vinters HV, Cloughesy TF, Mischel PS: Active matrix metalloproteinase 9 expression is associated with primary glioblastoma subtype. Clin Cancer Res 2002, 8:2894-2901

61. Lakka SS, Gondi CS, Dinh DH, Olivero WC, Gujrati M, Rao VH, Sioka C, Rao JS: Specific interference of urokinase-type plasminogen activator receptor and matrix metalloproteinase-9 gene expression induced by double-stranded RNA results in decreased invasion, tumor growth, and angiogenesis in gliomas. J Biol Chem 2005, 280: 21882-21892

62. Tews DS, Nissen A: Expression of adhesion factors and degrading proteins in primary and secondary glioblastomas and their precursor tumors. Invasion Metastasis 1998-1999, 18:271-284 
63. Lakka SS, Gondi CS, Yanamandra N, Olivero WC, Dinh DH, Gujrati M, Rao JS: Inhibition of cathepsin B and MMP-9 gene expression in glioblastoma cell line via RNA interference reduces tumor cell invasion, tumor growth and angiogenesis. Oncogene 2004, 23:4681-4689

64. Lakka SS, Gondi CS, Yanamandra N, Dinh DH, Olivero WC, Gujrati M, Rao JS: Synergistic down-regulation of urokinase plasminogen activator receptor and matrix metalloproteinase-9 in SNB19 glioblastoma cells efficiently inhibits glioma cell invasion, angiogenesis, and tumor growth. Cancer Res 2003, 63:2454-2461

65. Gondi CS, Lakka SS, Dinh DH, Olivero WC, Gujrati M, Rao, JS: Downregulation of UPA, UPAR and MMP-9 using small, interfering, hairpin RNA (siRNA) inhibits glioma cell invasion, angiogenesis and tumor growth. Neuron Glia Biol 2004, 1:165-176

66. Li Y, Guessous F, Kwon S, Kumar M, Ibidapo O, Fuller L, Johnson E, Lal B, Hussaini I, Bao Y, Laterra J, Schiff D, Abounader R: PTEN has tumor-promoting properties in the setting of gain-of-function p53 mutations. Cancer Res 2008, 68:1723-1731

67. Franchi A, Santucci M, Masini E, Sardi I, Paglierani M, Gallo O:
Expression of matrix metalloproteinase 1, matrix metalloproteinase 2, and matrix metalloproteinase 9 in carcinoma of the head and neck. Cancer 2002, 95:1902-1910

68. Rieber M, Strasberg Rieber M: DN-R175H p53 mutation is more effective than p53 interference in inducing epithelial disorganization and activation of proliferation signals in human carcinoma cells: role of E-cadherin. Int J Cancer 2009, 125:1604-1612

69. Liu J, Zhan M, Hannay JA, Das P, Bolshakov SV, Kotilingam D, Yu D Lazar AF, Pollock RE, Lev D: Wild-type p53: implications for soft tissue sarcoma growth and metastasis. Mol Cancer Res 2006 4:803-810

70. Martinez R, Rohde V, Schackert G: Different molecular patterns in glioblastoma multiforme subtypes upon recurrence. J Neurooncol 2010, 96:321-329

71. Furuta M, Weil RJ, Vortmeyer AO, Huang S, Lei J, Huang TN, Lee YS, Bhowmick DA, Lubensky IA, Oldfield EH, Zhuang Z: Protein patterns and proteins that identify subtypes of glioblastoma multiforme. Oncogene 2004, 23:6806-6814 